Review

\title{
Finite Element Modelling Approach for Progressive Crushing of Composite Tubular Absorbers in LS-DYNA: Review and Findings
}

\author{
Ali Rabiee and Hessam Ghasemnejad * (D)
}

Citation: Rabiee, A.; Ghasemnejad, H. Finite Element Modelling Approach for Progressive Crushing of Composite Tubular Absorbers in LS-DYNA: Review and Findings. J. Compos. Sci. 2022, 6, 11. https:// doi.org/10.3390/jcs6010011

Academic Editor: Stelios

K. Georgantzinos

Received: 16 November 2021

Accepted: 16 December 2021

Published: 29 December 2021

Publisher's Note: MDPI stays neutral with regard to jurisdictional claims in published maps and institutional affiliations.

Copyright: (C) 2021 by the authors. Licensee MDPI, Basel, Switzerland. This article is an open access article distributed under the terms and conditions of the Creative Commons Attribution (CC BY) license (https:// creativecommons.org/licenses/by/ $4.0 /)$.
Centre for Structures, Assembly and Intelligent Automation, Cranfield University, Cranfield MK43 0AL, UK; ali.rabiee@ruroc.com

* Correspondence: hessam.ghasemnejad@cranfield.ac.uk; Tel.: +44-(0)-1234-754395

\begin{abstract}
Robust finite element models are utilised for their ability to predict simple to complex mechanical behaviour under certain conditions at a very low cost compared to experimental studies, as this reduces the need for physical prototypes while allowing for the optimisation of components. In this paper, various parameters in finite element techniques were reviewed to simulate the crushing behaviour of glass/epoxy tubes with different material models, mesh sizes, failure trigger mechanisms, element formulation, contact definitions, single and various numbers of shells and delamination modelling. Six different modelling approaches, namely, a single-layer approach and a multi-layer approach, were employed with 2, 3, 4, 6, and 12 shells. In experimental studies, 12 plies were used to fabricate a $3 \mathrm{~mm}$ wall thickness GFRP specimen, and the numerical results were compared with experimental data. This was achieved by carefully calibrating the values of certain parameters used in defining the above parameters to predict the behaviour and energy absorption response of the finite element model against initial failure peak load (stiffness) and the mean crushing force. In each case, the results were compared with each other, including experimental and computational costs. The decision was made from an engineering point of view, which means compromising accuracy for computational efficiency. The aim is to develop an FEM that can predict energy absorption capability with a higher level of accuracy, around 5\% error, than the experimental studies.
\end{abstract}

Keywords: crashworthiness; composites; FEA; progressive crushing; LS-DYNA

\section{Introduction}

Two classes of finite element methods are available: either the implicit or explicit method [1]. The implicit method is widely available and used in a broad range of problems, including nonlinear stress analysis and static. The explicit method is widely used in highly nonlinear stress analysis and dynamics with contact-dominated problems. A car crash, for instance, or metal stamping simulations are applications well suited for the explicit method.

Due to the high cost of conducting experimental studies, there is a need for reliable computational models capable of predicting the crushing response of composite structures. There have been various attempts to develop explicit finite element models (FEMs), with different degrees of precision, for circular tubes [2-6], square tubes [4-13], angle-stiffeners [8], C-channels [8] and hat-stiffeners [14]. The classification of structural FEM can be divided into two groups. The first group is the micro-mechanical one [15-20]. In this group, the finite element models try to simulate the composite crushing phenomenon through a detailed modelling of its micromechanical behaviour. A very fine solid mesh is developed to accurately capture the micro-mechanics matrix crack propagation phenomenon. The computational effort demanded by this kind of model is very high, which makes it unpractical for engineering crash analysis. This approach is used mainly to perform simulations concerning the delamination phenomenon, in which the growth behaviour of a single crack is studied in a very detailed way [7]. The second group is the macro-mechanical one [3]. 
This type of model provides a macro-mechanical description of the material collapse. It is much more computationally effective, and consequently, it is a suitable choice for engineering crash analysis. However, it is not capable of precisely modelling all the main collapse modes that occur simultaneously during a crush event.

The FE modelling of composite structures can be either shell or solid elements. Solid element models require more computation time and are less widely used compared with shell elements used in the axial crushing of composite structures as mentioned above. A single layer [17,21-24] or multiple layers $[3,25]$ of shell elements can be used to model a laminate. In the single-layer model, this can be modelled as a single layer of shell elements, with each ply being represented by the thickness integration point, also referred to as the integration point in the thickness direction. This kind of model is not capable of modelling the interlaminar collapse modes shown by composites under crushing in an accurate way. However, it is useful if a detailed representation of the failure physics is not required and only load and energy level predictions are required. The main advantages are its simplicity and computational effectiveness, so for that point, they are highly suitable for practical engineering crash analysis. On the other hand, they have a notably lower level of robustness due to the large amount of parameter calibration required to obtain acceptable global results for a given test configuration [7].

The authors of [8] used this configuration for C-channel, angle-stiffeners and the hollow square tube modelling technique. In the multi-layer configuration model, the laminate is modelled by multiple shell elements, with each layer representing either a single ply or a group of plies, and the layers are glued together using an automatic contact definition (surface to surface).

In recent studies, the single-layer configuration model has been used to simulate the behaviour of various composite structures in the case of, for instance, thin-walled square sections. This method is capable of accurately capturing the local buckling and unstable collapse; however, due to the complex failure mechanism of composite structures, this method was ineffective in depicting the progressive failure process [4]. Providing precise input of key material properties and numerical parameters in the material model (e.g., eleven parameters in MAT 54), and defining the contact definition between the test specimen and the impactor and applying an all degrees of freedom constraint on the end of the test specimen, the single-layer model was able to yield good correlation with the experimental load-displacement graph for cross-sections studied in [8]. However, this configuration, as mentioned above, is not appropriate for failure mechanisms and the crushing behaviour, as these are mostly neglected.

The multi-layer modelling technique can be utilised for better capturing the failure process of the tubes undergoing progressive crushing [3-7]. However, in the multi-layer model, the correlation with the experimental load-displacement was not always satisfactory. The composite hollow tube was modelled in LS-DYNA using MAT 54 to analyse its crushing behaviour. The FEA results were satisfactory and agreed with the experimental load-displacement graphs; however, instead of the brittle failure mechanism observed in experimental studies, a significant local buckling of the tube was observed in FEA.

A finite element model was developed by [4]. This model was able to accurately predict the peak load of thin-walled square CFRP tube, although the specific energy absorption was underestimated by $33 \%$. In the FEA simulation, the crushed elements were deleted instead of forming debris, as was observed in the experiment. One of the parameters that contributed to the energy absorption was the debris formation wedged between the fronds of the tube's wall, which was neglected in the simulation. The author noted that this parameter alone affected the SEA value in a significant way. In $[5,6]$, the FEM was developed to capture the crushing behaviour of hollow circular and square tubes and compare the results with the experimental observations. It was noted by the authors that the model was not able to reproduce the axial matrix splits observed experimentally. This resulted in different load-displacement curves, deformation, and failure behaviour when compared with the experiment. Several parameters that influenced the crushing behaviour 
of square hollow tubes were analysed in [7]. The parameters were element size, number of shell layers, coefficient of friction and interlaminar material properties [26-28]. The author noted that by increasing the number of shells, the main collapse mode was unchanged. The influence of the friction coefficient between the tube and the machine plate and of the element dimension was also studied. The element size was coarse mesh $(7 \mathrm{~mm})$ and fine mesh $(4 \mathrm{~mm})$. The static friction coefficient values were $0.1,0.2$ and 0.3 , and the dynamic friction coefficient was kept constant at 0.65 . The increase in the friction coefficient from 0.1 to 0.3 and the use of finer mesh did not significantly change the crush zone morphology in the sense that all three tubes collapsed in the same way. For all three values of friction, the load-displacement curves have almost the same shape. In this sense, the effect of the friction variation was similar to a scaling of the magnitude of the load curves. The model with bigger elements shows a magnitude of force oscillation higher than the one shown by the refined model; however, the average force value is the same.

The authors of [10] combined a series of experimental investigations and examined their effect using finite element analysis and concluded proportional failure mechanisms leading to SEA, which is a result of dominated energy absorption mechanisms of approximately $60 \%$ material damage and 30\% friction with 10\% related to contact parameter [29]. Although a detailed examination of the material behaviour is essential to reach a load adapted lightweight design. Axial finite element modelling of composite structures uses different modelling methods. Various approaches were developed to obtain ideal forcedisplacement curves that are aligned with experimental data. One approach includes a hybrid mesh of shell and solid elements to capture ideal load-displacement curves [30]. This method is used for modelling of crack propagation with finite cohesion elements [31] that consist of shell elements representing the material and a solid element to represent delamination failure. Alternatively, material 54 in LS-DYNA is used to predict crushing behaviour and the idealised force-displacement graph [32]. One strategy is the SOFT parameter implemented in LS-DYNA to map pre-damage and consequently create a progressive crashfront of CFRP square tubes or composite sections, and the author concluded that Mat_Composite_Damage of LS-DYNA for GFRP box structures was found to be in accordance with experimental results when it was modelled as a double-shell configuration. Some similar conclusions were obtained by other researchers that used multi-shell configuration, which can predict energy absorption and maximum force under crushing [32,33].

Abdallah [34] numerically optimised fibre orientation of glass/phenolic tubes under tensile and compression loadings. Failure parameters in the Mat_54 material card in the LSDYNA Library are defined by ALPH (shear stress parameter for the nonlinear term), BETA weighting factor for the shear term in tensile fibre mode), FBRT (softening for fibre tensile strength), YCFAC (reduction factor for compressive fibre strength after matrix failure), TFAIL (time step size criteria for element deletion), SOFT (softening reduction factor for material strength in the crashfront element) and EFS (effective failure strain) to improve the accuracy of the final results. Abdallah concluded that the developed numerical models are capable of predicting tensile and compression loading of small and large scale GFRP specimens within $10 \%$ discrepancy. This trial-and-error or parametric study approach has also been used in References [34-38]. However, in another study by Xiao [39], axial crushing of braided carbon tubes was modelled using MAT58 in LS-DYNA to predict peak forces within $20 \%$ of the experimental values, but the predicted crushing forces and SEA were generally lower than experimental results. This is likely due to a deficiency in MAT_58 in modelling the subsequent unloading response of partially damaged material.

Many studies focused on the contact parameter [29], crack propagation modelling with de-cohesion elements [40] or user-defined material model, which requires extensive experimental investigations [41].

In [42,43], the effect of failure trigger mechanisms on the energy absorption capability of CFRP tubes under axial compression is experimentally and numerically investigated. The conventional approach to introduce a failure mechanism is to apply a $45^{\circ}$ chamfer on one end, and the failure could initiate progressively. Alternatively, an attachment 
of crush-cap can be utilised to initiate the progressive crushing. Two different types of crush-caps were studied, each causing the crushed material to fold either inward or splay outward. The effect of the corner radius of the crush-caps on the peak load, SEA, and crush behaviour was investigated. The author noted that the chamfer failure trigger was most effective at reducing the initial peak load while maintaining a high-sustained crush load and specific energy absorption (SEA). The inward-folding failure trigger approach was not as effective at reducing the initial peak load but was more effective than using a chamfer for maintaining a high-sustained crush load and SEA. However, the modelling technique of the simulation, which was based on a multi-shell configuration with failure a trigger, showed a high level of correlation with the experimental results for both the chamfer and combined failure trigger cases. The simulation was able to predict key deformation characteristics, which were observed during the experimental crushing process, and progression of matrix splits and the direction of splaying of plies.

In the modelling approach, it is necessary to develop models that are simple enough to be employed in practical analysis situations but at the same time capable of providing results with a suitable level of accuracy. At the same time, the approach shall be numerically robust and practical in the model build phase [44-46].

The primary focus of this study is to develop a 'multi-layer' finite element modelling approach to capture the crushing behaviour of composite tubular structures. This approach requires a series of parametric studies to maximise prediction of FEM, i.e., failure trigger mechanism to initiate a progressive crushing, materials card formulation, delamination interface, element formulation, mesh sensitivity and number of shells. This paper illustrates the effect of the named parameters on the predictability of developed FEM compared to experimental studies.

The modelling techniques further investigate the effect of various loading on the crushing behaviour of composite tubes. The experimental and FEA results are compared based on force-displacement curves. The approach of FEM is categorised based on parameters affecting energy absorption capability and the ability of the model to capture real-life crashing and composite material behaviour. Hence, this review paper has covered the essential parameters and calibration procedures to establish the findings.

\section{LS-DYNA Software}

A commonly used piece of software for crashworthiness application by industry and academics is LS-DYNA, which was developed by LSTC and is suited for highly nonlinear transient dynamic finite element analysis.

LS-DYNA, within the past decade, has added many new features such as new material types, contact algorithms, element formulation, etc. LSTC has gradually expanded to develop a universal tool for most implicit and most vastly used explicit coding for aerospace, automotive, military and construction. LS-DYNA has its own pre-processor called LS-PrePost.

\subsection{Material Models}

New material models are developed and added to LS-DYNA regularly. Approximately 200 material models are implemented in the software. For unidirectional composite materials, these material models narrow down to the following [47]:

1. Material mode-22: Composite Damage

2. Material model - 54 and 55: Enhanced Composite Damage

3. Material model-58: Laminated Composite Fabric

4. Material model -59: Shell/Solid Composite Failure Model

Other material models are adopted to predict composite behaviour, i.e., MAT_161 and MAT_162, where the matrix phase is modelled within the material card and also these material cards can be used to model both unidirectional or bidirectional fibres; however, the concentration of this paper is to isolate material cards from the matrix phase.

Material properties such as shear modulus, elastic modulus, and Poisson's ratio are essential parameters for a material model. Strength properties for failure analysis are 
also essential to predict material behaviour. These properties are transverse compressive strengths, longitudinal compressive strength, transverse tensile strength and shear strength. Each model has an option to determine the material axes, such as local and global orthotropic material axes. For a given geometry and load, the process of calculation is in three steps,

1. Stress and strain distributions around the stress concentrated areas are calculated,

2. Failure (maximum) load is predicted,

3. Mode of failure is determined.

The analysis consists of two major parts: stress analysis and failure analysis. The most often used material models are described with parametric studies to compare the differences.

\subsubsection{MAT_022: Composite Damage Model}

This is the first composite failure material model implemented in LS-DYNA, which was proposed by Chang-Chang [48,49]. The keyword for this model is *MAT_COMPOSITE_DAMAGE or *MAT_022. This model can be used in solid and shell elements. By using the user-defined integration rule, the constitutive constants vary through the thickness of the shell.

MAT-022 uses three criteria defined by Chang-Chang and five material parameters to define failure modes.

The three failure criteria used are:

1. A fibre breakage failure mode,

2. A compression failure mode,

3. A matrix failure mode.

The five material parameters are:

1. Shear Strength, $S_{2}$,

2. Traverse tensile strength, $S_{12}$,

3. Transverse compressive strength, $C_{2}$,

4. Longitudinal tensile strength, $S_{1}$,

5. Nonlinear shear stress parameter.

The matrix cracking failure mode is determined from Equations (1) and (2),

$$
\begin{gathered}
F_{\text {matrix }}=\left(\frac{\sigma_{2}}{S_{2}}\right)^{2}+\bar{\tau}=1 \\
\bar{\tau}=\frac{\frac{\tau_{12}^{2}}{2 G_{12}}+\frac{3}{4} \alpha \tau_{12}^{4}}{\frac{S_{12}^{2}}{2 G_{12}}+\frac{3}{4} \alpha S_{12}^{4}}
\end{gathered}
$$

The failure is assumed when $F_{\text {matrix }}$ is less than 1 , then $E_{2}, G_{12}, v_{1}$ and $v_{2}$ are set to zero. The compression failure is determined from Equation (3). Failure is assumed when $F_{\text {comp }}$ is less than 1 and $E_{2}, v_{1}$ and $v_{2}$ are set to zero.

$$
F_{\text {comp }}=\left(\frac{\sigma_{2}}{2 S_{12}}\right)^{2}+\left[\left(\frac{\sigma_{2}}{2 S_{12}}\right)-1\right] \frac{\sigma_{2}}{C_{2}}+\bar{\tau}=1
$$

The fibre breakage failure mode is determined from Equation (4). Failure is assumed when $F_{\text {fibre }}$ is less than 1 , then $E_{1}, E_{2}, G_{12}, v_{1}$ and $v_{2}$ are set to zero.

$$
F_{\text {fibre }}=\left(\frac{\sigma_{1}}{S_{1}}\right)^{2}+\bar{\tau}=1
$$

where $E_{1}$ and $E_{2}$ are the longitudinal and transverse elastic moduli, respectively, $G_{12}$ is the shear modulus, and $v_{1}$ and $v_{2}$ are the in-plane Poisson's ratios. $C_{2}$ and $S_{2}$ are the transverse compressive strength and shear strength, $S_{1}$ is the longitudinal tensile strength and $S_{12}$ is the in-plane shear strength, and $\alpha$ is the nonlinear shear stress parameter. 


\subsubsection{MAT_54-55: Enhanced Composite Damage Model}

These material models are improvised versions of the Chang-Chang composite damage model. The keyword for this model is *MAT_ENHANCED_COMPOSITE_DAMAGE or *MAT_054 or *MAT_055. This model is used for thin shells only. When the model is undamaged, the material is assumed to be orthotropic and linear elastic, and when the damage occurs, nonlinearity is introduced into the material. Material 54 is suggested by Chang, which is called the Chang matrix failure criterion, and material 55 is suggested by Tsai-Wu, which is called the Tsai-Wu matrix failure criterion. These two models have very similar formulations.

Material 54 is the same as material 22 but with added compressive fibre failure mode, and it also includes compressive and tensile fibre failure and compressive and tensile matrix failure modes.

The Chang-Chang criterion (MAT_54) is given below,

Tensile fibre $\left(\sigma_{11}>0\right)$.

$$
\left(\frac{\sigma_{11}}{S_{1}}\right)^{2}+\bar{\tau}=1
$$

All moduli and Poisson's ratios are set to zero when the tensile fibre failure criteria are met, that is $E_{1}=E_{2}=G_{12}=v_{12}=v_{21}=0$. All the stresses in the elements are reduced to zero, and the element layer has failed. Where $E_{1}$ and $E_{2}$ are the longitudinal and transverse elastic moduli, respectively, $\mathrm{G}_{12}$ is the shear modulus, $v_{12}$ and $v_{21}$ are the in-plane Poisson's ratios.

Failure mode for compressive fibre $\left(\sigma_{11}>0\right)$,

$$
\left(\frac{\sigma_{11}}{S_{12}}\right)^{2}=1
$$

For this mode, $E_{1}=v_{12}=v_{21}=0$

Failure mode for tensile matrix $\left(\sigma_{11}>0\right)$,

$$
\left(\frac{\sigma_{22}}{S_{2}}\right)^{2}+\bar{\tau}=1
$$

For this mode, $E_{2}=G_{12}=v_{21}=0$

Failure mode for compressive matrix

$$
\left(\frac{\sigma_{22}}{2 S_{12}}\right)^{2}+\left[\left(\frac{C_{2}}{2 S_{12}}\right)-1\right] \frac{\sigma_{22}}{C_{2}}+\bar{\tau}=1
$$

where $\bar{\tau}$ and other parameters are defined in the above section. For this mode, $E_{2}=G_{12}$ $=v_{12}=v_{21}=0$. For brittle material, when the failure criterion is met, a reduction factor is applied to reduce the compressive fibre strength, and a softening factor is used to reduce tensile fibre strength.

When the nonlinear shear stress parameter is set to 0 , all the above failure criteria reduce to the original failure criteria of Hashin [43].

Material model 55 formulation is very close to the material model 54 . It uses the Tsai-Wu failure criteria [50] for compressive and tensile matrix failure modes, which are given in single expression as follows:

$$
\frac{\sigma_{22}^{2}}{C_{2} S_{2}}+\left(\frac{C_{2}}{S_{12}}\right)^{2}+\frac{\left(C_{2}-S_{2}\right) \sigma_{22}}{C_{2} S_{2}}=1
$$

This material model (Mat_055) is similar to the Chang-Chang failure model except for the compressive and tensile matrix failure mode, which is replaced with the above expression and transverse shear parameters in this material model.

In the material input, additional parameters such as effective failure strain and maximum strains are required besides strengths. When the strains values are reached, then the 
element is deleted. The element is removed when failure occurs in all the composite layers, and these layers are defined through shell thickness integration points.

Elements having the same nodes with the deleted elements become "crashfront" elements. By using a softening reduction factor, the strengths can be reduced and become moduli of the crashfront elements; this fact results in a stable crushing process and, consequently, a sudden release of stress concentration is compensated. To understand the strain parameters, a four-node single-shell element undergoes a tensile load in the direction of the fibre, see Figure 1. The material and strength properties are taken from [51]. SOFT takes into account the softening strength effects on the crashfront elements by scaling down the initial input strength.

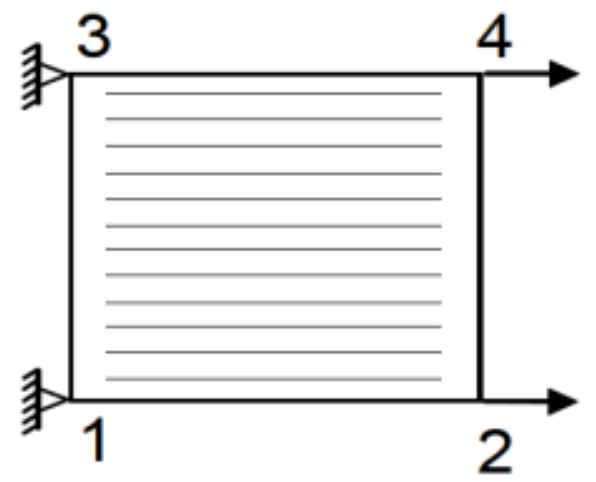

Figure 1. Single 4-node shell element under tension [51].

Initially, the element is loaded at a constant strain rate of $1 / \mathrm{s}$ in the fibre direction. The stress in the element increases linearly in the fibre direction up to the maximum value, and all elastic properties and stresses are reduced to zero in 100 time steps, as shown in Figure 2. The maximum strain for fibre tension is set to a default value of 0 .

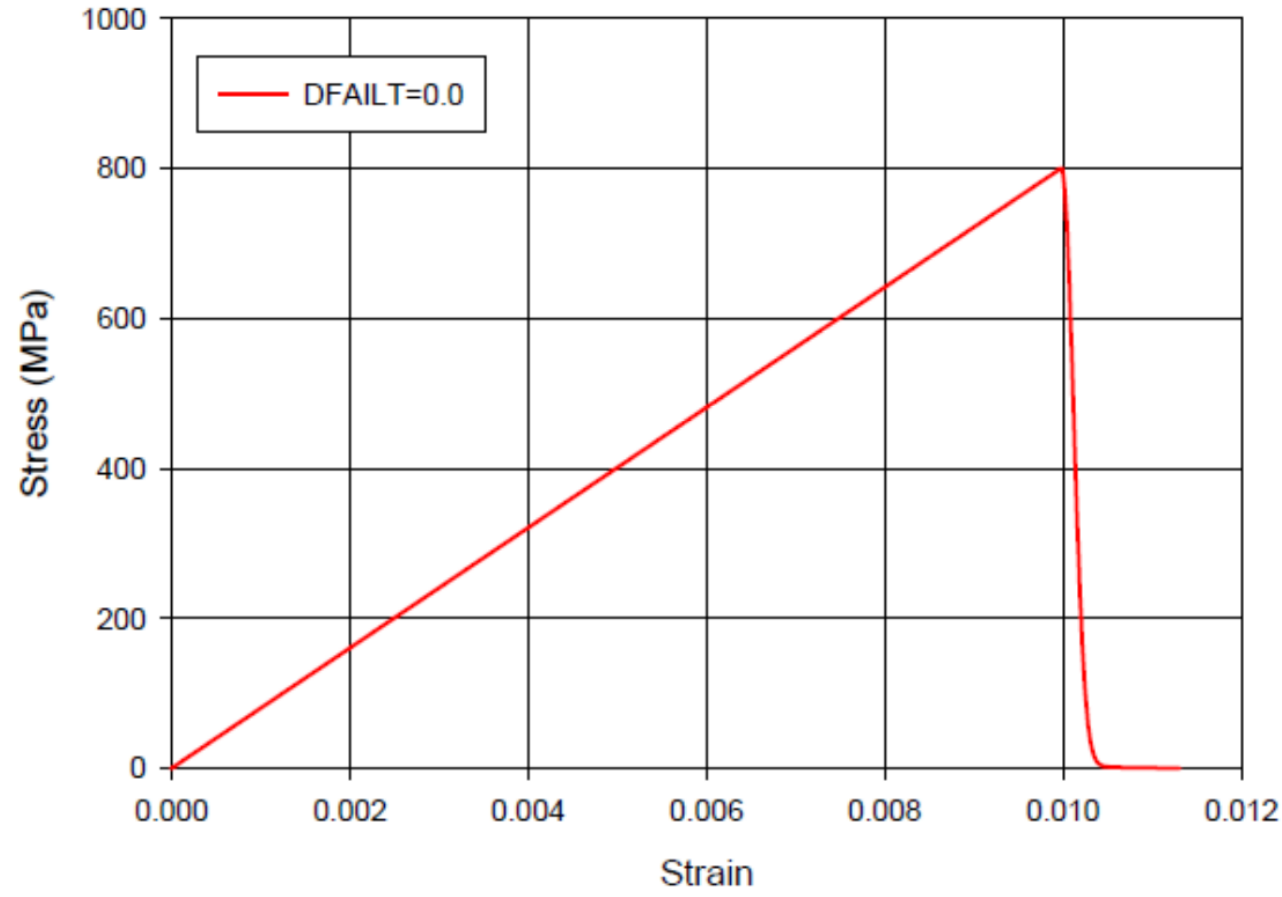

Figure 2. Stress-strain curve in fibre direction under tension, DFAILT $=0.0$ [51].

Then, all the elastic properties and stresses are kept constant except the maximum strain for fibre tension, which is set to 0.02 . After the value of maximum stress is reached, 
the elastic constants and the stresses remain constant until the maximum strain value is reached, then the element is deleted, immediately resulting in the stress being reduced to zero, as shown in Figure 3.

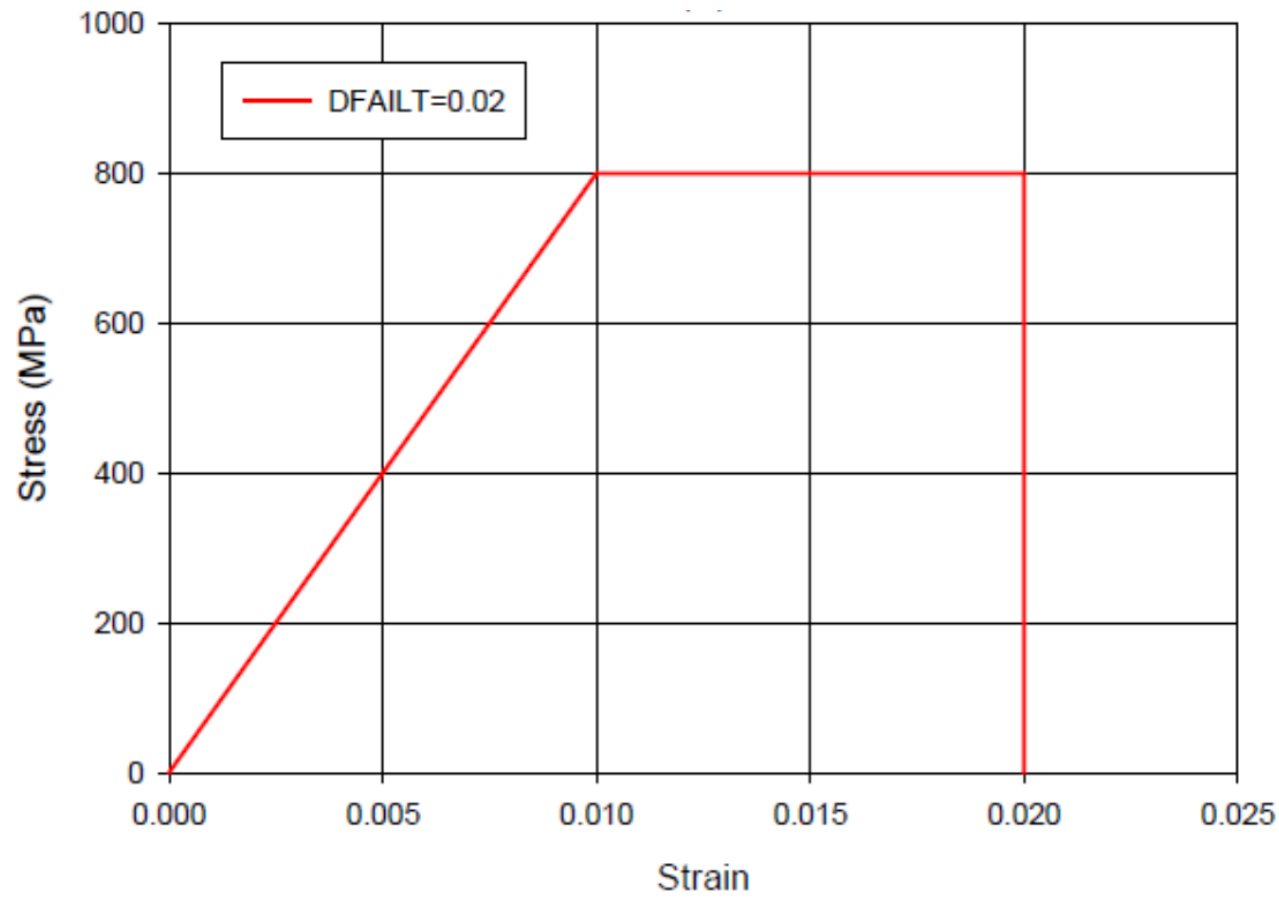

Figure 3. Stress-strain curve in fibre direction under tension, DFAILT $=0.02$ [51].

Stresses are kept constant when compressive matrix and fibre criteria are met. In material models 54 and 55, ultimate failure can occur in any four different ways:

1. Chang-Chang failure criterion is satisfied in tensile fibre mode,

2. Maximum fibre tensile strain is met,

3. Maximum effective failure strain is met,

4. Minimum time step is met.

Softening Reduction Factor (SOFT)

A crashfront parameter is used to reduce the crush failure. This parameter is the softening reduction factor for the element material strength that nodes share of the crushed element. By default, this value is set to 1, which means that the element contains $100 \%$ of its strength, and when this value drops to 0.5 , it indicates that the raw elements that share the same nodes of crashfront elements have only $50 \%$ of its original strength.

In numerical parameters, SOFT is considered as one of the influential parameters that could amend the shape of the force-displacement curve to match with the experimental results. For every geometric structure, this parameter value needs to be amended through trial and error to obtain a good agreement with the numerical and experimental forcedisplacement results. The SOFT parameter can be found in materials 54, 55, 58 and 59. This parameter can be activated by giving a positive value for TFAIL in materials 54 and 55 , which is the time step size for element deletion, and by giving a positive value for TSIZE in materials 58 and 59, which is the time step for element deletion. When this time step is reached, the element is deleted. When the degree of curvature of the structure is higher, then the structure is more efficient in crushing by fragmentation. For lower value, the structure gives frond formation. These large fronds are accompanied by long delamination, which results in creating an effective damage length that is inefficient for energy absorption. Francesco Deleo, Wade, Paolo Feraboli [8] simulated the model using material 54 in LS-DYNA and noted that by using the SOFT parameter, the damage length 
can be changed by this parameter to reduce the material strength of the row of the element that is ahead of the crashfront. Sivarama Krishnamoorthy [52] showed that the crashfront parameter influences the mean crushing force in the force-displacement curve. Therefore, it can be concluded that the SOFT parameter significantly influences the amount of energy absorption. As the value of SOFT increases, more energy is absorbed by the composite structure due to the higher strength of the structure. Other authors claimed the similar conclusions [53-55]

\subsubsection{MAT_58: Laminated Composite Fabric Failure Model}

Based on the strain-based failure surface, this model can be used for modelling composite materials, which have unidirectional layers, woven fibres and laminates. The keyword for this model is *MAT_LAMINATED_COMPOSITE_FABRIC or *MAT_058. This model is used for shell elements only. This model is implemented in LS-DYNA by Matzenmiller, Lubliner and Taylor [56], which is also called an MLT composite model and is based on a plane stress continuum damage mechanic model.

In material 58, Hashin failure criteria [49] are used with changes for different types of composites. The maximum effective strain is applicable for element layer failure for any different type of composites.

\subsubsection{MAT_59: Composite Failure Model}

This material model is also called an elastic-plastic material model, which is an enhanced version of Mat_022. It works on the basis of failure surfaces, which are: faceted failure surfaces and ellipsoidal failure surfaces. It will be able to model the progressive material failure due to many failure criterions, which includes longitudinal and transverse directions in tension and compression, respectively, and through-thickness direction in compression and shear.

\subsection{Delamination Models}

Delamination modelling has several approaches in LS-DYNA. Tiebreak contacts have been vastly used, and it is proven to be a robust contact algorithm and relatively simple. Depending on the model of study, different contacts can be employed to achieve better prediction.

One-way contact types allow for compression loads to be transferred between the slave nodes and the master segments. Tangential loads are also transmitted if relative sliding occurs when contact friction is active. A Coulomb friction formulation is used to transition from static to dynamic friction. This transition requires that the static friction coefficient is larger than the dynamic friction coefficient and a decay coefficient is defined. The one-way contact is used to indicate that only the user-specified slave nodes are checked for penetration of the master segments.

The algorithm ties nodes that are initially in contact by creating a linear spring, and the debonding of the surface initiates when the maximum stress criterion is met, which leads to scaling down of the stress by a linear damage curve until the critical separation is reached and the spring is removed [47].

$$
\left(\frac{\sigma_{n}^{2}}{N F L S}\right)^{2}+\left(\frac{\sigma_{S}^{2}}{S F L S}\right)^{2}=1
$$

In which $\sigma_{n}$ and $\sigma_{s}$ are the normal and shear stresses acting at the interface, and NFLS, SFLS and PARAM are the normal and shear strength of the tie and critical distance, respectively. Once the damage is initiated, the two surfaces begin to separate, and the interfacial stresses are then scaled down as a linear function of the separation distance. $P A R A M$ is the critical distance at which the failure occurs (i.e., deletion of tiebreak and advancing of delamination) [53].

$$
\text { PARAM }=\frac{2 \times E_{\text {tie }}}{S}
$$


where:

$$
S=\sqrt{\max \left(\sigma_{n}, 0\right)^{2}+\left(\sigma_{s}^{2}\right)^{2}}
$$

Due to the failure of the tiebreak interface, $E_{t i e}$ is the energy released. With trial and error procedures, a sensitivity study was conducted of Mode-I and Mode-II to determine their relative effect(s) on the tiebreak failure process. It can be noted that for composite crushing simulations, Mode-I fracture is a dominant mode of failure during the tiebreak failure process. Thus, to simplify the simulations, a pure Mode-I delamination was assumed.

$$
G_{I C}=\frac{1}{2} \sigma_{n} P A R A M
$$

In Equation (13), the critical normal separation of the surface is determined, named PARAM, based on the energy release rate in Mode-I $\left(G_{I C}\right)$ and the critical normal stress.

The laminate of the open cross-sections was modelled as multi-shell configurations of shell elements, with each layer representing a various number of plies. In Section 4.7, the effect of the number of plies in each shell was investigated based on energy absorption capability. Hence, the tiebreak was adopted for each case of study and the tiebreak contact was defined only between these shell layers, rather than between individual plies. However, delamination could occur along any of the plies, and if not all ply interfaces, during specimen crushing, as was observed experimentally [56-66]. To account for the energy dissipated by these additional delamination interfaces, PARAM was scaled by the ratio of the number of ply interfaces $n_{\text {delamination }}$ to the number of tiebreak interfaces $n_{\text {tie }}$ defined as:

$$
P A R A M^{\prime}=P A R A M \times \frac{n_{\text {delamination }}}{n_{\text {tie }}}
$$

based on the experimental observations, it was assumed that delamination occurred among all plies. The values that were used and calculated in Equations (13) and (14) are listed in Table 1.

Table 1. Tiebreak input parameters [59-66].

\begin{tabular}{cccccccc}
\hline$E_{1}(\mathrm{GPa})$ & $E_{2}(\mathrm{GPa})$ & $\begin{array}{c}G_{I C} \\
\left(\mathbf{k J} / \mathbf{m}^{2}\right)\end{array}$ & $\begin{array}{c}G_{I I C} \\
\left(\mathbf{k J} / \mathbf{m}^{2}\right)\end{array}$ & $\begin{array}{c}\text { NFLS } \\
(\mathbf{M P a})\end{array}$ & $\begin{array}{c}\text { SFLS } \\
(\mathbf{M P a})\end{array}$ & $\begin{array}{c}\text { PARAM } \\
(\mathbf{m m})\end{array}$ & $\begin{array}{c}\text { PARAM' } \\
(\mathbf{m m})(\mathbf{2} \text { Shells) }\end{array}$ \\
\hline $39 \pm 3$ & $11.8 \pm 1$ & 1.2 & 0.9 & 22.5 & 57.3 & 0.025 & 0.15 \\
\hline
\end{tabular}

\subsection{Laminate Stiffness}

Laminate stiffness is critical in designing composite structures. In crashworthiness, this can be a critical factor due to the complexity of energy transfer and dissipation through the structure against occupant safety. Four major categories are considered during the composite design approach,

1. Cost,

2. Mass,

3. Stiffness,

4. Geometrical stability.

Stiffness can be calculated from load-deflection graphs:

$$
\text { Stiffness }=\frac{\text { Total Load }}{\text { Deflection }}
$$

Equation (15) can help with experimental studies and obtaining the general performance from a specimen. However, due to the orthotropic behaviour of composite materials, the stiffness of a laminate, either symmetric or antisymmetric, depends on the angle of fibres, materials, and thickness of the plies, which can zero out some elements of the three 
stiffness matrices [A], [B] and [D]. This is known as ABD Matric and is used to calculate composite laminate stiffness. The stiffness matrix in the principal directions is:

$$
[C]=\left[\begin{array}{ccc}
\frac{E_{1}}{1-v_{12} v_{21}} & \frac{v_{12} E_{2}}{1-v_{12} v_{21}} & 0 \\
\frac{v_{21} E_{1}}{1-v_{12} v_{21}} & \frac{E_{2}}{1-v_{12} v_{21}} & 0 \\
0 & 0 & G_{12}
\end{array}\right]
$$

These elements may result in reducing or zeroing out the coupling of forces, normal and shear forces, and twisting and bending moments. Hence, a balanced lay-up sequence can reduce or zero bending moments in a laminate, which improves mechanical performance under various loading conditions. It can be proved that the coupling matrix $[\mathrm{B}]=0$ for symmetric laminates, and hence, the force and moment equations can be decoupled.

$\left[\begin{array}{c}N_{x} \\ N_{y} \\ N_{x y}\end{array}\right]=\left[\begin{array}{lll}A_{11} & A_{12} & A_{16} \\ A_{12} & A_{22} & A_{26} \\ A_{16} & A_{26} & A_{66}\end{array}\right]\left[\begin{array}{c}\varepsilon_{x}^{0} \\ \varepsilon_{y}^{0} \\ \gamma_{x y}^{0}\end{array}\right]\left[\begin{array}{c}M_{x} \\ M_{y} \\ M_{x y}\end{array}\right]=\left[\begin{array}{ccc}D_{11} & D_{12} & D_{16} \\ D_{12} & D_{22} & D_{26} \\ D_{16} & D_{26} & D_{66}\end{array}\right]\left[\begin{array}{c}k_{x} \\ k_{y} \\ k_{x y}\end{array}\right]$

A laminate is called quasi-isotropic if its extensional stiffness matrix [A] behaves similar to that of an isotropic material. This not only implies $A_{11}=A_{22}, A_{16}=A_{26}$, and $A_{66}=\left(A_{11}-A_{12}\right) / 2$ but also that these stiffnesses are independent of the angle of rotation of the laminate. It is called quasi-isotropic and not isotropic because [B] and [D] may not behave as an isotropic material. Examples of quasi-isotropic laminates include $[0 / \pm 60]$, $[0 / \pm 45 / 90] \mathrm{s},[0 / 36 / 72 /-18 /-54]$.

\section{Simulation Setup}

For the simulations, an Explicit FE LS-DYNA code is used with a multi-layered shell configuration to reduce numerical costs. Composite tubes were modelled as multi-layers of Belytschko-Tsay circular shell elements with one integration point in the element plane to represent the direction of the stacking sequence. In double-shell configuration, the GFRP innermost shell has six integration points, with another six integration points being assigned to the outermost shell to represent all twelve UD layers. In a GFRP tube, each individual layer has a thickness of $0.25 \mathrm{~mm}$. The total thickness of both shells is $3 \mathrm{~mm}$. Each fibre orientation is assigned with insertion of an integration point with respect to the stacking sequence used with its associated thickness. The material properties are obtained from [56,59,60]; see Table 2.

Table 2. Material properties of GFRP (TenCate E772) [56-60].

\begin{tabular}{ccccccccc}
\hline \multicolumn{10}{c}{ GFRP (TenCate E772) } \\
\hline$E_{\mathbf{1}}(\mathbf{G P a})$ & $\boldsymbol{E}_{\mathbf{2}} \mathbf{( G P a )}$ & $G_{\mathbf{1 2}} \mathbf{( G P a )}$ & $v_{12}$ & $\begin{array}{c}\sigma_{u} \mathbf{0}^{\circ} \\
\mathbf{( M P a}\end{array}$ & $\begin{array}{c}\sigma_{u} \mathbf{9 0}^{\circ} \\
\mathbf{( M P a}\end{array}$ & $\begin{array}{c}\boldsymbol{\tau}_{\boldsymbol{s}} \\
\mathbf{M P a})\end{array}$ & $\begin{array}{c}V_{f} \\
\mathbf{( \% )}\end{array}$ \\
\hline $39 \pm 3$ & $11.8 \pm 1$ & $3.2 \pm 0.5$ & 0.29 & $836 \pm 20$ & $29 \pm 2$ & $97 \pm 4$ & 58 \\
\hline
\end{tabular}

In shell theory, the thickness of the shell is considered as mid-plane. In double-shell configuration, two shells with radiuses of 37.75 and $39.25 \mathrm{~mm}$ to represent the inner and outer shells with lengths of 80 and $77.5 \mathrm{~mm}$ were modelled, respectively, using LS-PrePost representing the GFRP tube geometry. Each shell was glued to itself so that the triggering at the top of the shell would not detach during the crushing process, as a separate shell was used. In this triggering approach, two shells were used, one with $2.5 \mathrm{~mm}$ in height acting as the trigger (one element size), and the other, depending on whether it was the inner or outer shell, had its representative height assigned. Therefore, the top shell in each FEA case study represents the trigger. The quadrilateral shell element was used with each element size of $2.5 \times 2.5 \mathrm{~mm}$. The trigger mechanism was modelled by reducing the first-row thickness of the shell elements to represent the bevel trigger, from 1.5 to 
$0.05 \mathrm{~mm}$ in each shell. A solid element rigid block was modelled to represent the striker. The LS-DYNA material model of Enhanced_composite_damage (Mat_54-55), which is an orthotropic material, with the failure criterion of Chang-Chang was used. This failure criterion is a modification of Hashin's failure criterion for assessing lamina failure. The hourglass was set at $10 \%[3-7,43,53]$.

Modelling interlaminar separation or delamination failure (Mode-I) requires either detailed experimental investigation for the cohesive zone or three-dimensional representation that both result in an increase in computational and experimental costs. Delamination failure causes energy absorption, and this can be modelled with a multi-layered shell configuration with a contact card that is capable of a $G_{I C}$-implemented energy release rate [40-43]. The One_Way_Surface_To_Surface_Tiebreak contact between the two shells is defined, with the inner tube being the master and the outer being the slave.

Tiebreak contacts allow the modelling of interlaminar debonding, which transmits both compressive and tensile forces with optional failure criteria. The tiebreak option enables the detachment of the contact surfaces by creating springs between two surfaces, and after reaching maximum normal stress (NFLS) or shear stress (SFLS), if the failure parameter, driven by occurring normal and shear stresses, become 1, the contact forces soften linearly until contact distance $P A R A M$ is reached and the interface failure is completed. Based on the interlaminar utilisation of the contact, the parameters are determined by the mechanical properties of the matrix material. Consequently, shell layers detach when the interlaminar stress exceeds the matrix properties, which are mainly responsible for interlaminar strength. Maximum normal and shear contact stresses for the tiebreak contact is based upon the mechanical properties of the epoxy resin. The maximum contact distance is set to $0.15 \mathrm{~mm}$. Automatic_Node_To_Surface contact was defined for the striker and inner shell, with the striker being the master and the inner shell being the slave. The Automatic_Single_Surface contact algorithm was utilised. This prevents penetration of the crushing tube by its own nodes.

To satisfy quasi-static conditions, it is important that the load is applied in a manner that would yield a minimal inertial effect on the results, and the ratio of the kinetic energy to the internal energy must be reasonably small. Time-scaling was utilised to apply the load at a higher rate to reduce total simulation time. A constant loading rate of $0.65 \mathrm{~m} / \mathrm{s}$ was applied, and the kinetic energy to the internal energy was less than $10 \%$ upon initial contact and less than 5\% throughout the remainder of the crushing process.

All bottommost nodes of all shell element layers are constrained in their translational degrees of freedom. The impactor is modelled rigidly with a mass of $108.4 \mathrm{~kg}$ and a velocity of $7.022 \mathrm{~m} / \mathrm{s}$. Gravity is modelled with an acceleration factor of $9.81 \mathrm{~m} / \mathrm{s}^{2}$. All simulation results are smoothed using an SAE $300 \mathrm{~Hz}$ filter [43].

\section{Finite Element Modelling}

\subsection{Delamination Interface}

Many researchers have used friction to simulate delamination, e.g., [56-60]. Friction influences the energy absorption capability; however, using friction influences the SEA value, increases friction between the shells, and causes a higher SEA value (see Section 5.3), and this compared with experimental data cannot be considered as a correct FEM. Due to this, a different approach was considered. Tiebreak option 8 was utilised instead of friction to model delamination as this contact card can define the Mode-I and Mode-II energy release rate, which simulates delamination.

The tiebreak contact definition implemented in LS-DYNA allows for the simulation of delamination at the interface between adjacent shell element layers. Tiebreak Option 8 formulations were investigated for this study, namely, tiebreaks with a bilinear tractionseparation law. This requires interlaminar normal and shear strengths and a critical distance to interface failure as input parameters to model delamination in crush simulations [10]. However, the optimal critical failure distance parameter selection has not been thoroughly studied in the open literature. The formulation of required input parameters, such as 
interlaminar normal and shear strengths, fracture toughness under pure Mode-I and ModeII loading, and interfacial stiffness for normal and shear modes; a description of the model setup using each formulation is explained in Section 4.3.1. To determine the energy rate of Mode-I and Mode-II, DCB and 3ENF tests were carried out.

DCB test determines the Mode-I energy release rate $\left(G_{I}\right)$ for delamination growth. Unidirectional GFRP with resin E722 was used to manufacture 20 by $150 \mathrm{~mm}$ specimens with stacking sequence of $(-45,45,0,90)$ s. A thin Teflon film is placed at the mid-plane to avoid bonding and develop a pre-determined crack at $60 \mathrm{~mm}$. The samples are cured at 120 degrees Celsius for an hour and a half under composite vacuum pressure in a sealed bag wrapped in breather cloth and two metal sheets to evenly apply pressure on the laminates. The delaminated end of the specimen is attached to two metal tabs. Load is then applied on the metal tabs to create a crack growth on the specimen at a rate of $2 \mathrm{~mm} / \mathrm{min}$ (quasi-static). This is carried out by taking the difference in crack lengths. Unidirectional GFRP with resin E722 was used to manufacture 20 by 150 by $6 \mathrm{~mm}$ specimens according to ESIS standard with a stacking sequence of $(-45,45,-45,45,0,90,0,90,0,90,0,90)$ s to carry out three end-notched flexure tests. The input parameters of tiebreak contact option 8 are shown in Table 2.

\subsection{Boundary Conditions and Contact Definitions}

The loading striker was modelled as a rigid body. The tubes were placed in the Zdirection upright and the loading striker at the chamfered end of the tube. The interaction between the loading striker and the tube was modelled using a node-to-surface contact definition (automatic contact from node to surface). The tiebreak contact definition between the shell layers not only facilitates the simulation of delamination but also prevents layers from penetrating each other after the tiebreak has failed, as the contact definition would remain in effect. In summary, Automatic_Node_To_Surface contact was defined for the striker and inner shell with striker being the master and inner shell being the slave. The Automatic_Single_Surface contact algorithm was utilised. This prevents penetration of the crushing tube by its own nodes, which is due to the sticker's nodes potentially causing disturbance to the model and the inner shell penetrating its own nodes and elements. All bottommost nodes of all shell element layers are constrained in their translational degrees of freedom.

\subsection{Material Model}

Material models Mat_022, Mat_054-055, Mat_058 and Mat_059 were used to capture an ideal initial peak and mean crushing force against computational costs. These parameters determine the reliability and the ability of these material models in cylindrical composite structures. The initial peak illustrates the stiffness of the material, and the mean crushing force shows the progressive crushing behaviour. In this section, the computational cost is one of the main parameters of case consideration. The time taken for the simulation to converge against the extracted results can be compromised to ideally have a model that converges within a reasonable timeframe and its effect on the extracted results. All bottommost nodes of all shell element layers are constrained in their translational degrees of freedom.

\subsubsection{Material Modelling of Mat-045-055}

This model allows the user to create a local material coordinate system to specify the orientation of each ply. There are 21 parameters in Mat_54 that need to be specified, 15 of which are physical parameters and 6 are numerical parameters [47]. From the 15 physical parameters, 10 parameters are material constants, the values of which were obtained from $[55,59,60]$, as shown in Table 1 . The remaining five physical parameters are the tensile and compressive failure strains (element deletion strains) in the fibre direction (DFAILT and DFAILC), the matrix and shear failure strains (DFAILM and DFAILS), and the effective failure strain (EFS). The six numerical parameters can be adjusted to yield desired material 
behaviour. Based on an extensive parametric study, it was concluded that of these six parameters, the crashfront element softening parameter (SOFT) is of key importance to this study. This parameter reduces the strength of elements surrounding a damaged or deleted element.

As mentioned, there are five physical parameters (failure strains) and six numerical parameters in MAT54 whose values need to be determined numerically. A comprehensive parametric study was performed to investigate the effect of these parameters on the simulated load-displacement behaviour. It was determined that the physical parameter DFAILC (fibre compression failure strain) had the greatest effect on the value of initial peak load while the numerical parameter SOFT (crashfront element softening parameter) had the greatest effect on the value of sustained crush load, which determined the value of SEA.

Parameters DFAILT, DFAILM and DFAILS (shear failure strains) were found to have a marginal effect on the results and were kept constant at arbitrarily selected values of $0.02,0.02$ and 0.03 , respectively. However, increasing the DFAILM value increased computational cost unreasonably (see Section 6.1). It was found that simulations with DFAILC $=-0.004$ and SOFT $=0.75$ yielded the mean crushing force value and displacement behaviour for chamfered tubes that matched very well with experimental data, as shown in Tables 3 and 4.

Table 3. The parametric study shows the effect of DFAILC in MAT54 on the peak load, crush and SEA of the circular tube [66].

\begin{tabular}{cccc}
\hline DFAILC & $\begin{array}{c}\text { Peak Load } \\
(\text { Num/Exp\%) }\end{array}$ & $\begin{array}{c}\text { Crush Load } \\
\text { (Num/Exp\%) }\end{array}$ & SEA (Num/Exp\%) \\
\hline-0.0100 & $157.9 \%$ & $159.2 \%$ & $166.1 \%$ \\
\hline-0.007 & $67.2 \%$ & $86.9 \%$ & $87.2 \%$ \\
\hline-0.006 & $80.3 \%$ & $86.9 \%$ & $87.2 \%$ \\
\hline-0.005 & $106.2 \%$ & $86.9 \%$ & $87.2 \%$ \\
\hline-0.004 & $102.2 \%$ & $86.9 \%$ & $87.2 \%$ \\
\hline-0.003 & $94.1 \%$ & $86.9 \%$ & $87.2 \%$ \\
\hline
\end{tabular}

Table 4. The parametric study shows the effect of SOFT in MAT54 on the peak load, crush and SEA of the circular tube [66].

\begin{tabular}{cccc}
\hline SOFT & $\begin{array}{c}\text { Peak Load } \\
\text { (Num/Exp\%) }\end{array}$ & $\begin{array}{c}\text { Crush Load } \\
\text { (Num/Exp\%) }\end{array}$ & SEA (Num/Exp\%) \\
\hline 0.75 & $102.2 \%$ & $103.4 \%$ & $101.1 \%$ \\
\hline 0.80 & $102.2 \%$ & $116.2 \%$ & $125.8 \%$ \\
\hline 0.85 & $102.2 \%$ & $137.6 \%$ & $138.8 \%$ \\
\hline 0.90 & $102.2 \%$ & $153.8 \%$ & $159.4 \%$ \\
\hline
\end{tabular}

A parametric study was conducted to determine the optimal values of the unknown parameters for the multi-layer modelling approach. The resultant values are presented in the above tables. This developed FEM, with the SOFT parameter set to $0.75(75 \%)$ and DFAILC set to -0.004 , can produce an accurate prediction of experimental results. The DFAILC value is negative due to compression.

\subsubsection{Material Model Results}

Figure 4 shows a comparison of the material models in the previous sections. MAT022 has an initial peak of $141 \mathrm{kN}$ with a mean crush force of $13 \mathrm{kN}$, and the displacement reaches $70 \mathrm{~mm}$ with a computational cost of $14 \mathrm{~h}$. In comparison with the experimental data, this material model is inaccurate at predicting the experimental material behaviour. 
MAT_054-055, on the other hand, illustrates an ideal prediction of material prediction, with an initial peak value of $80 \mathrm{kN}$, mean crushing force of $67 \mathrm{kN}$, displacement of $33 \mathrm{~mm}$ and computational cost of $28 \mathrm{~h}$. In comparison with the experimental data, which included an initial peak of $78 \mathrm{kN}$ and mean crush force of $69 \mathrm{kN}$, Mat_054-055 was on average $5 \%$ off. Mat_058 illustrated that it over-predicts the mean crushing force by $7 \mathrm{kN}$, although the initial peak value has been improved to $79 \mathrm{kN}$ compared with Mat_054-055. The displacement reduced to $31 \mathrm{~mm}$ and the computational cost increased to $36 \mathrm{~h}$. The difference between the two material models lays in the mean crushing force, and Mat_058 over predicts, which results in a reduction in the displacement value, resulting in greater difference to the experimental data, with a $7.5 \%$ overall difference. Mat_059, which is a modified version of Mat_022, has shown greater improvement in the prediction of crushing behaviour in composites. However, the initial peak is $10 \mathrm{kN}$ off, the mean crushing force value is underpredicted by $11 \mathrm{kN}$, and the displacement value is $36 \mathrm{~mm}$. The overall difference is $9 \%$. The computational cost value is $45 \mathrm{~h}$.

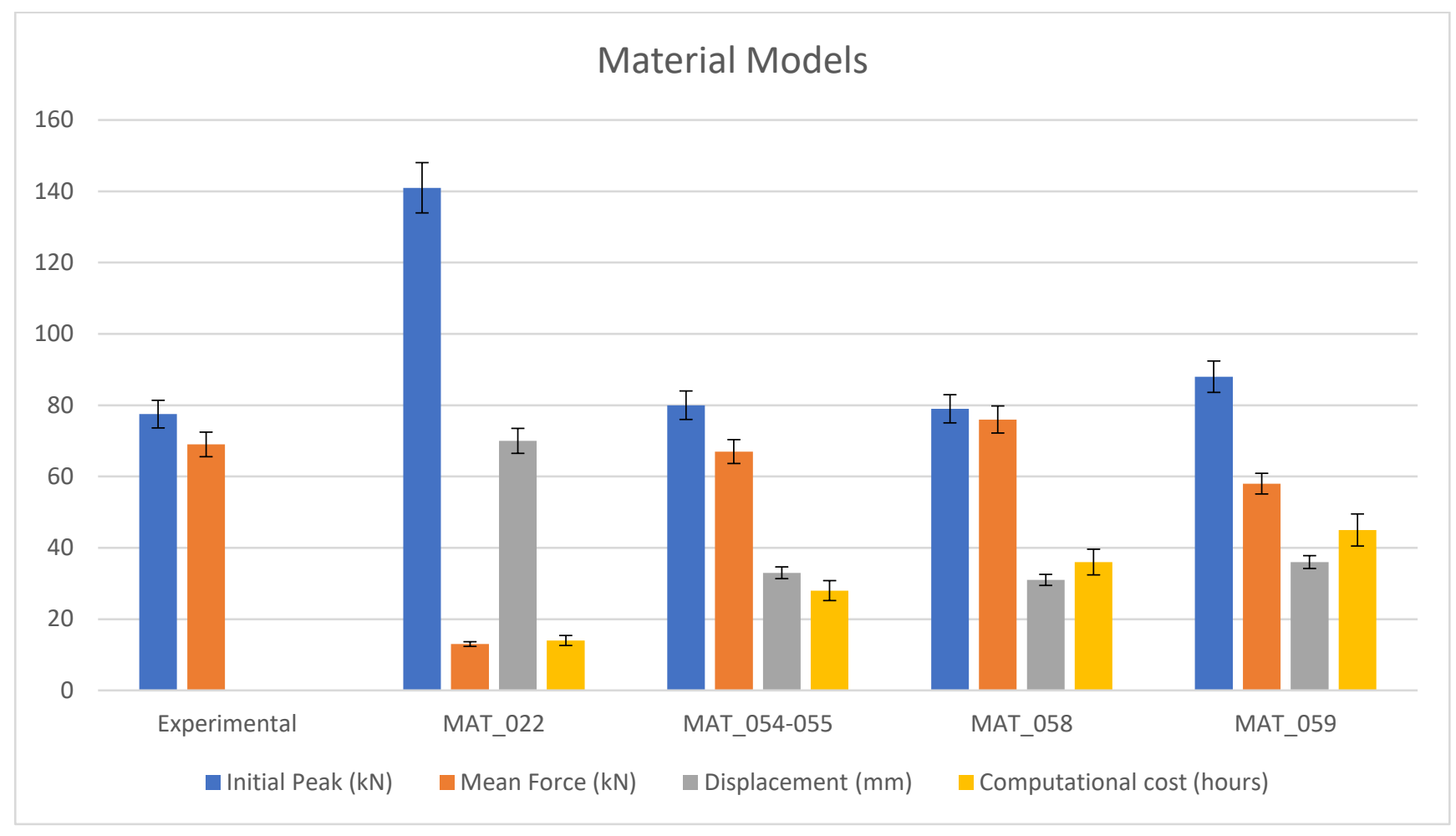

Figure 4. Material model comparison [66].

By considering all four reviewed parameters, Mat_054-055 can predict the material behaviour with respect to the energy absorption capability and having a reasonable computational cost compared with the extracted results, as predicted by $[3-7,43,53,59,60]$.

\subsection{Element Formulation}

The possibility of using under-integrated elements results in a reduction in computational cost and compromises the accuracy of the prediction. To compare the performances, several relevant element formulations were employed, and the results have been discussed. The relevant chosen element formulations are Hughes-Liu, S/R Hughes-Liu, S/R corotational Hughes-Liu, fully integrated and Belytschko-Tsay (default). In consideration of this test, since energy absorption capability is the main concern, the parameters chosen are the initial peak, mean crush force and displacement; however, in numerical studies, the computational cost plays a major role, and therefore, this parameter is also considered. 
Figure 5 shows the differences between the chosen element formulations against the reference parameter of experimental data. The result of Hughes-Liu element formulation showed an initial peak of $82 \mathrm{kN}$, mean crush force value of $90 \mathrm{kN}$ with displacement of $27 \mathrm{~mm}$, and computational cost of $105 \mathrm{~h}$. The total difference in performance value was $13 \%$ compared with experimental data. The extracted result from S/R Hughes-Liu showed an initial peak of $81 \mathrm{kN}$, mean crush force of $65 \mathrm{kN}$ and displacement of $34 \mathrm{~mm}$, and the computational cost was $115 \mathrm{~h}$. The mean difference from the experimental data was $7 \%$.

\section{Element Formulation}

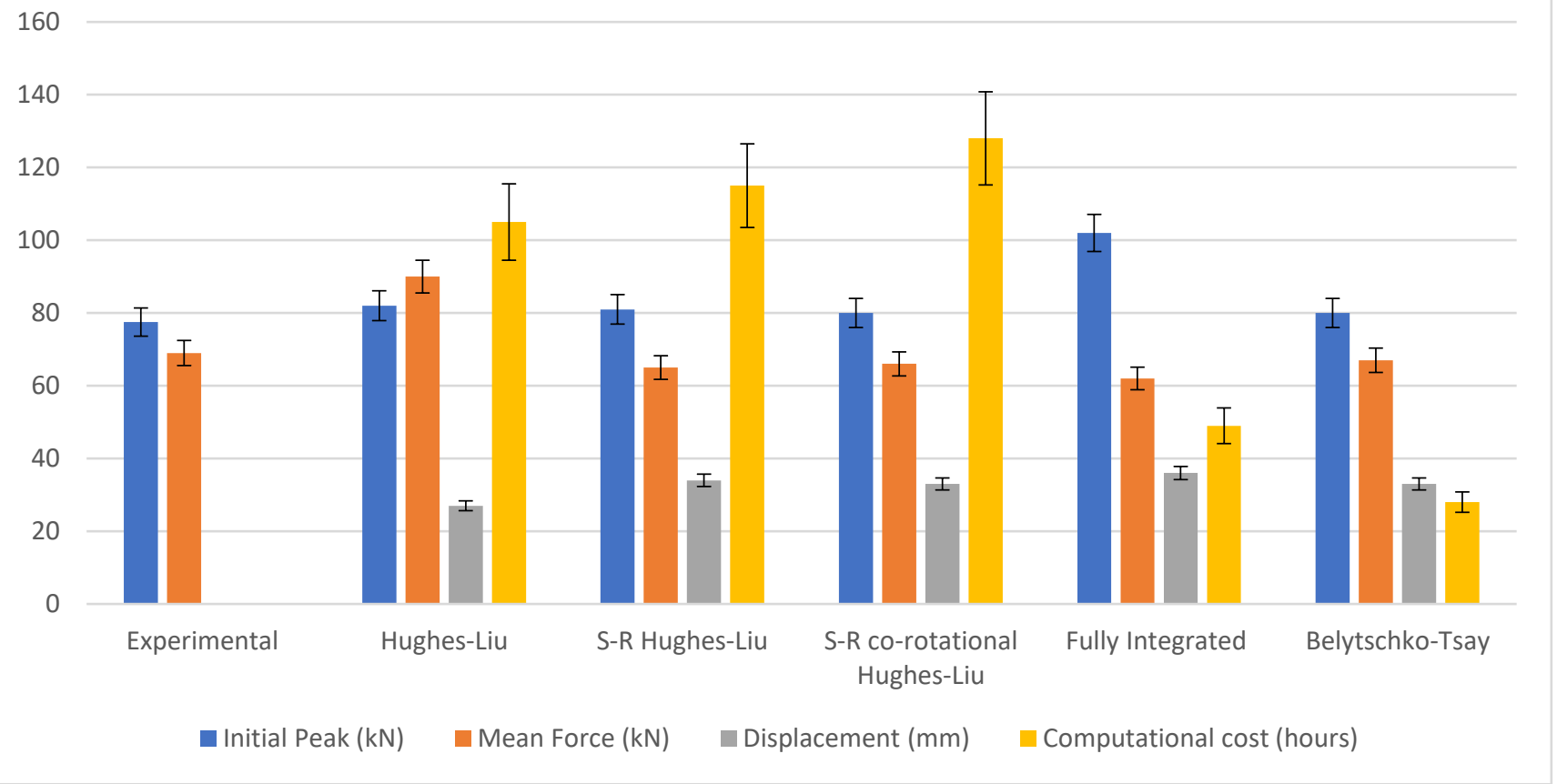

Figure 5. Element formulation comparison [66].

Both element formulations have staggering computational costs with around 4 to 5 days to converge each of the simulations. The results obtained from S/R co-rotational Hughes-Liu showed an initial peak value of $80 \mathrm{kN}$, mean crush force of $66 \mathrm{kN}$, displacement of $33 \mathrm{~mm}$ and computational cost of $128 \mathrm{~h}$. Fully integrated element formulation, on the other hand, was off by 24 and $7 \mathrm{kN}$ in the initial peak value and mean crush force, respectively. Although the computational cost is much lower compared with mentioned element formulations, both element formulations were off by $6 \%$ and $12 \%$, respectively.

The Belytschko-Tsay element formulation, which is the default parameter in LSDYNA, was rather close to the experimental data with a computational cost of $28 \mathrm{~h}$. The initial peak value was $80 \mathrm{kN}$, mean force value was $67 \mathrm{kN}$, and the displacement was $33 \mathrm{~mm}$, with a total mean difference of $5 \%$.

By taking into account all four reviewed parameters, the Belytschko-Tsay element formulation is the cheapest computational cost compared with other element formulations, as supported by other researchers $[3-7,43,53,59,60]$, which leads to the use of this type of element formulation hereafter.

\subsection{Mesh Size}

In numerical modelling, one of the influential parameters is the mesh size. The mesh sensitivity test is beneficial for establishing a mesh size regarding a specific model to obtain an acceptable accuracy. In a numerical study, compromising acceptable accuracy for 
computable costs is also relatively important. Six different element sizes were modelled with 5.5, 4.5, 3.5, 2.5, 1.5, $0.5 \mathrm{~mm}$ quad elements (see Figure 6).
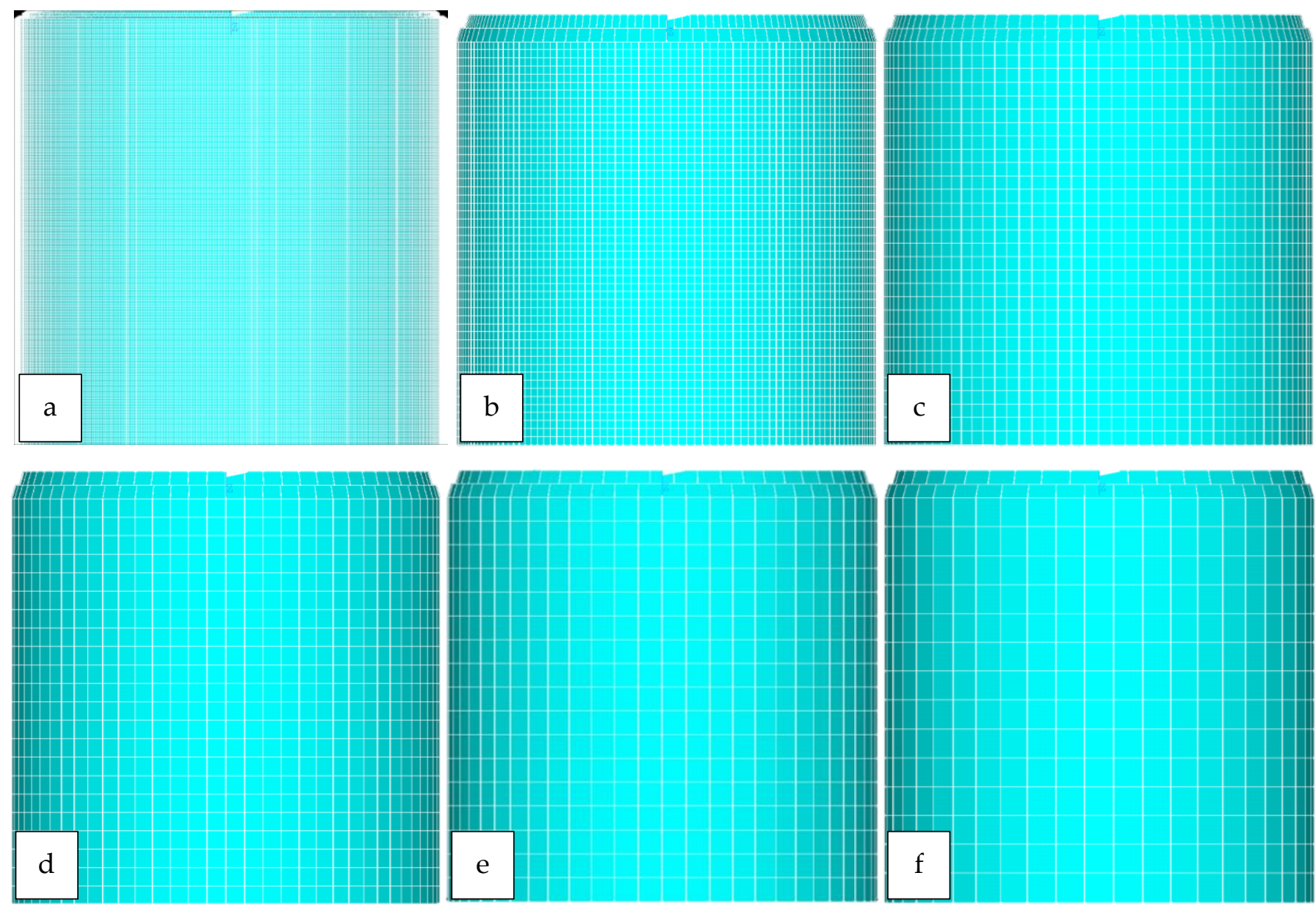

Figure 6. Mesh sensitivity models. (a) 0.5, (b) 1.5, (c) 2.5, (d) 3.5, (e) 4.5, (f) $5.5 \mathrm{~mm}$ [66].

From a design point of view, the aim is to achieve the cheapest model in terms of computational cost and predict energy absorption capability with an acceptable accuracy. As the mesh becomes increasingly finer, the computational cost increases dramatically, and relatively higher accuracy is achieved. A balance of the two needs to be chosen in that the energy absorption capability of the model is within an acceptable range and the computational cost is within an acceptable range.

Figure 7 shows the mesh sensitivity comparison of the modelled mesh sizes mentioned in Figure 6. The results illustrate a noticeable fact that the mesh $5.5 \mathrm{~mm}$ size is too coarse with very high peak forces and low mean crushing force, with $86 \mathrm{kN}$ difference between the two. This mesh size has the lowest computational cost; however, the result is nearly $40 \%$ off from the experimental data. As the mesh size becomes smaller, the accuracy improves. At $4.5 \mathrm{~mm}$, the results improved from the $5.5 \mathrm{~mm}$ case study, although the difference is $29 \%$ and at $3.5 \mathrm{~mm}$, the difference is $18 \%$. The peak is higher than the experimental study by $8 \mathrm{kN}$, and the mean crushing force is lower by $7 \mathrm{kN}$.

At a mesh size of $2.5 \mathrm{~mm}$, the result is in line with experimental data. The difference is $5 \%$, and the computational cost is lower than the mesh size of 1.5 and $0.5 \mathrm{~mm}$ by $170 \%$ and $280 \%$, respectively. Although the accuracy is $1.5 \%$ for both cases, the balanced case to accurately calculate and predict energy absorption is $2.5 \mathrm{~mm}$, which is supported by many studies $[43,53,59,60]$. 


\section{Mesh Sensetivity}

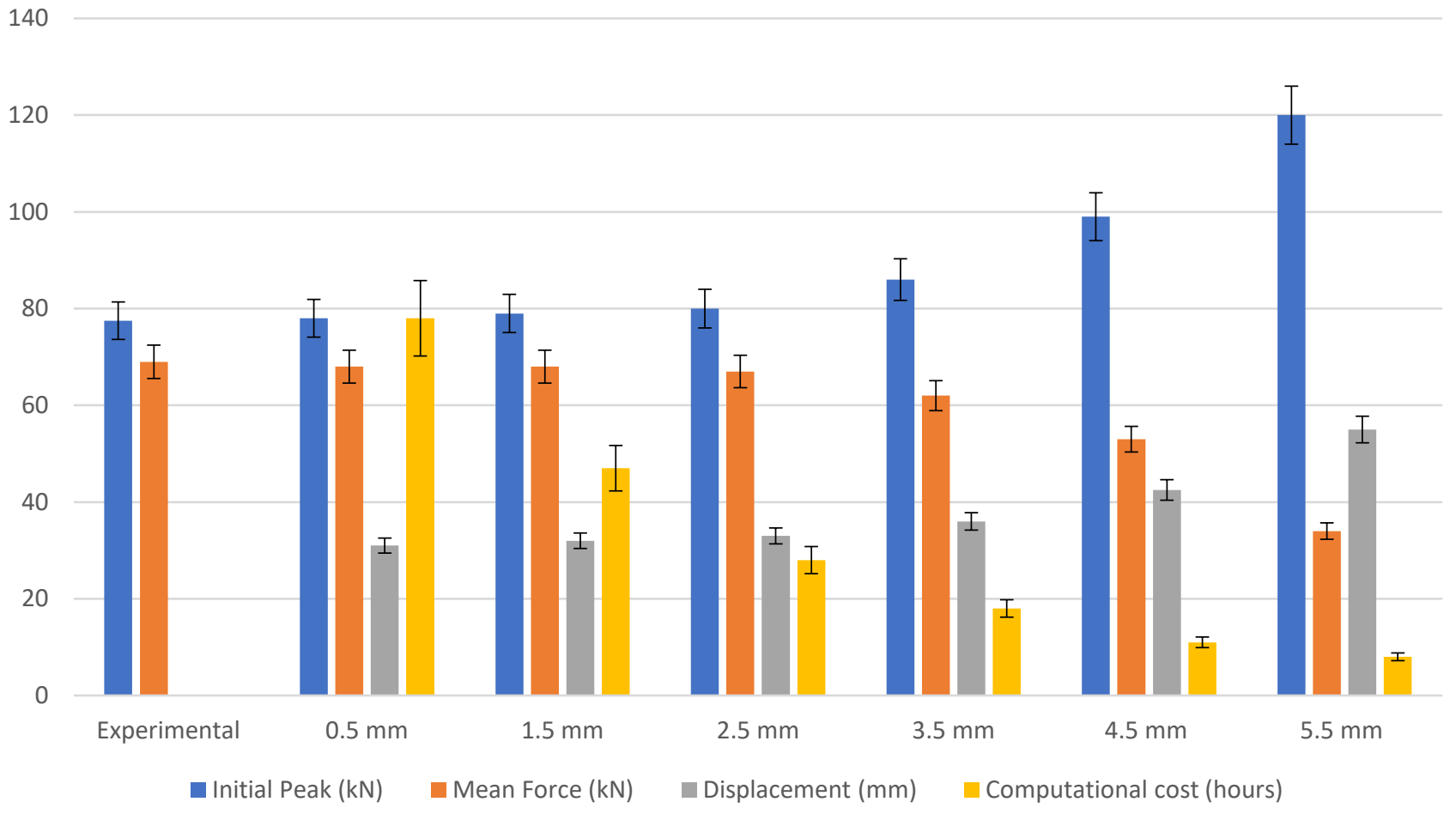

Figure 7. Mesh sensitivity comparison [66].

\subsection{Trigger Modelling}

In experimental studies, a $45^{\circ}$ bevelled trigger mechanism was utilised, and similarly, in numerical studies, a suitable trigger mechanism is needed to initiate the progressive failure that matches the experimental studies. The maximum crush force in the FEA model tends to be overestimated significantly [10,54]. Few approaches were raised to study the effect of different trigger mechanisms on the initial peak value of the load and mean crushing force (see Figure 8). These case studies are, (a) single-shell with no trigger, (b) single-shell inward-chamfer, (c) single-shell outward-chamfer, (d) double-shell level size inward-chamfer, (e) double-shell with $2.5 \mathrm{~mm}$ shell size difference inwardchamfer, (f) double-shell with $2.5 \mathrm{~mm}$ shell size difference outward-chamfer, (g) doubleshell with $2.5 \mathrm{~mm}$ shell size difference inward-chamfer with different reduced element sizes, (h) double-shell with $5 \mathrm{~mm}$ shell size difference inward-chamfer, (i) double-shell with $2.5 \mathrm{~mm}$ shell size difference inward and outward-chamfer.

The results from the case studies are compared in Figures 9 and 10. The aim of this research is to find the optimum finite element modelling case to obtain a prediction of the initial peak force value.

Single-shell configuration with trigger mechanism has shown better peaks and mean crushing force prediction (case b and c) than the one without the trigger mechanism (case a). However, the double-shell configuration has led to better prediction with less than $5 \%$ error compared with experimental data. Outward-chamfer in all cases lead to an increase in computational costs with lower mean crushing force. Cases (e) and (f) have shown better prediction of the initial peak values of 80 and $78 \mathrm{kN}$. The configurations of the two are similar in sectioning and positioning of the shells, with the outer shell being $2.5 \mathrm{~mm}$ (one element size) shorter than the inner shell. However, the difference lays in the computational costs, in which the outward-chamfer, as shown in all cases, increases by $5-15 \mathrm{~h}$. Furthermore, the trigger mechanism affects progressive crushing behaviour. The mean crushing force in case (f) has a lower value than the one in case (e). 

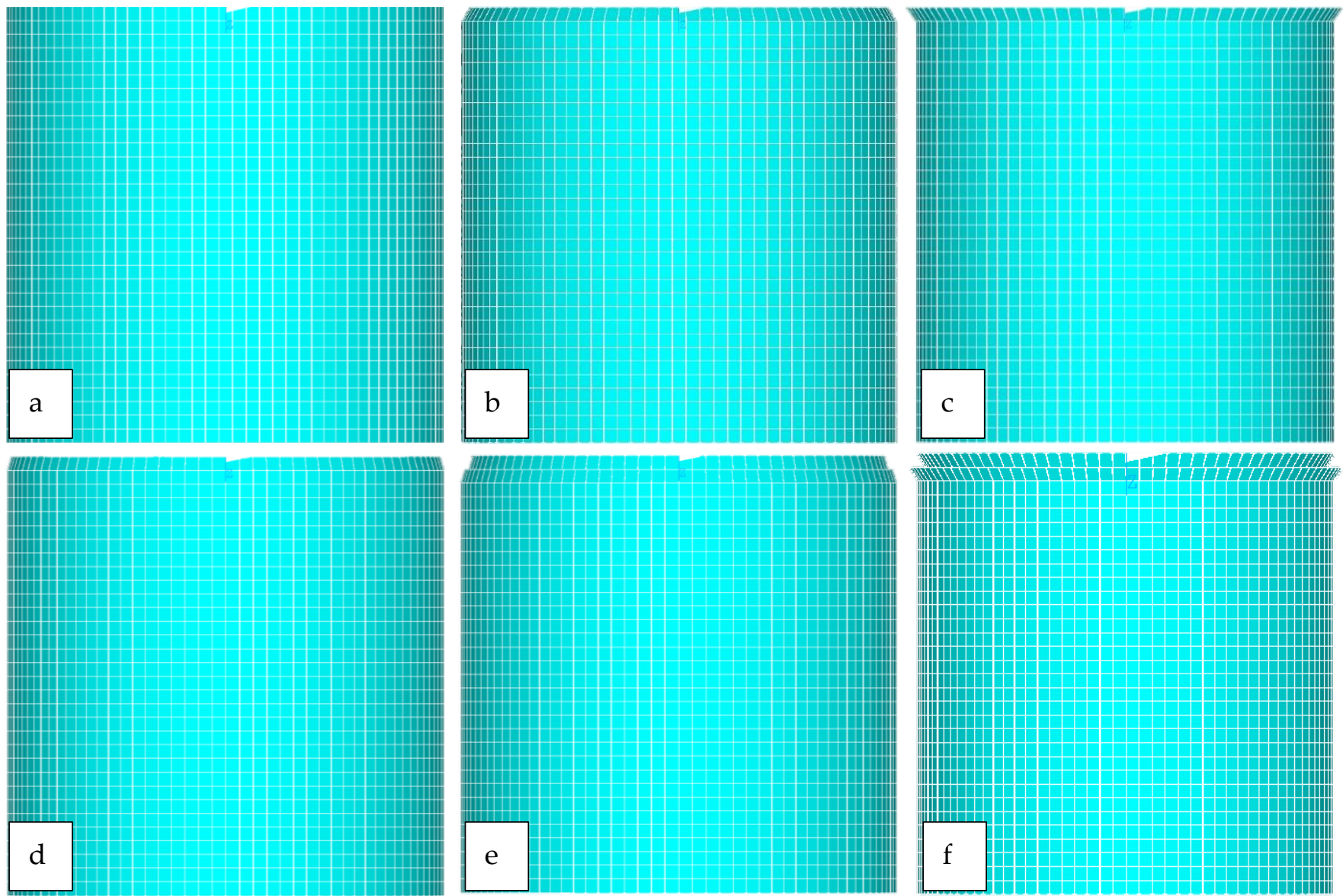

reduced element size to $5 \mathrm{e}-6 \mathrm{~m}$

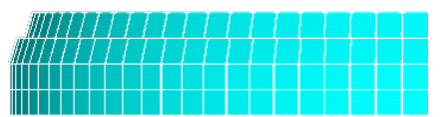

reduced element size to $5 \mathrm{e}-5 \mathrm{~m}$

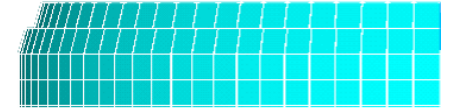

reduced element size to $5 \mathrm{e}-4 \mathrm{~m}$

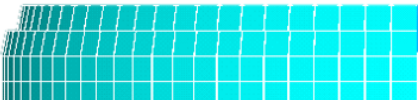

reduced element size to $5 \mathrm{e}-3 \mathrm{~m}$
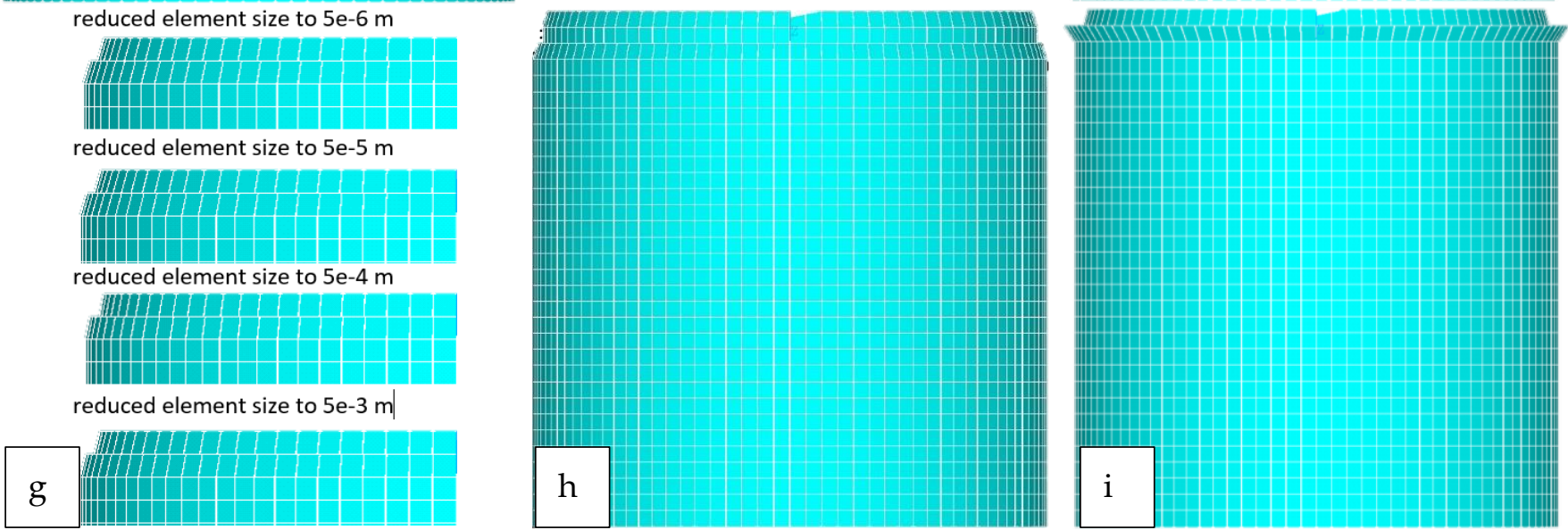

Figure 8. Trigger mechanism modelling cases, (a) single-shell no trigger, (b) single-shell inwardchamfer, (c) single-shell outward-chamfer, (d) double-shell level size inward-chamfer, (e) double-shell $2.5 \mathrm{~mm}$ shell size difference inward-chamfer, (f) double-shell $2.5 \mathrm{~mm}$ shell size difference outwardchamfer, (g) double-shell $2.5 \mathrm{~mm}$ shell size difference inward-chamfer different reduced element sizes, (h) double-shell $5 \mathrm{~mm}$ shell size difference inward-chamfer, (i) double-shell $2.5 \mathrm{~mm}$ shell size difference inward and outward-chamfer [65].

Case (g) is based on case (e), and the configuration of the trigger is the same. In this trigger mechanism, the element size is reduced to a smaller size, and this acts as the trigger mechanism. This technique is supported by [43,44,59,60]. In Figure 10, the reduced element sizes are compared against their initial peak value and mean crushing force and computational costs. It can be concluded that as the element size becomes thicker, the peak 
value increases and from $0.05 \mathrm{~mm}$ onwards, and this reduction in element size has no effect on initial peak value.

The prevailing case that matches experimental results is a $2.5 \mathrm{~mm}$ sectioned doubleshell configuration with an inward-chamfering trigger mechanism and a reduced element size of $0.05 \mathrm{~mm}$.

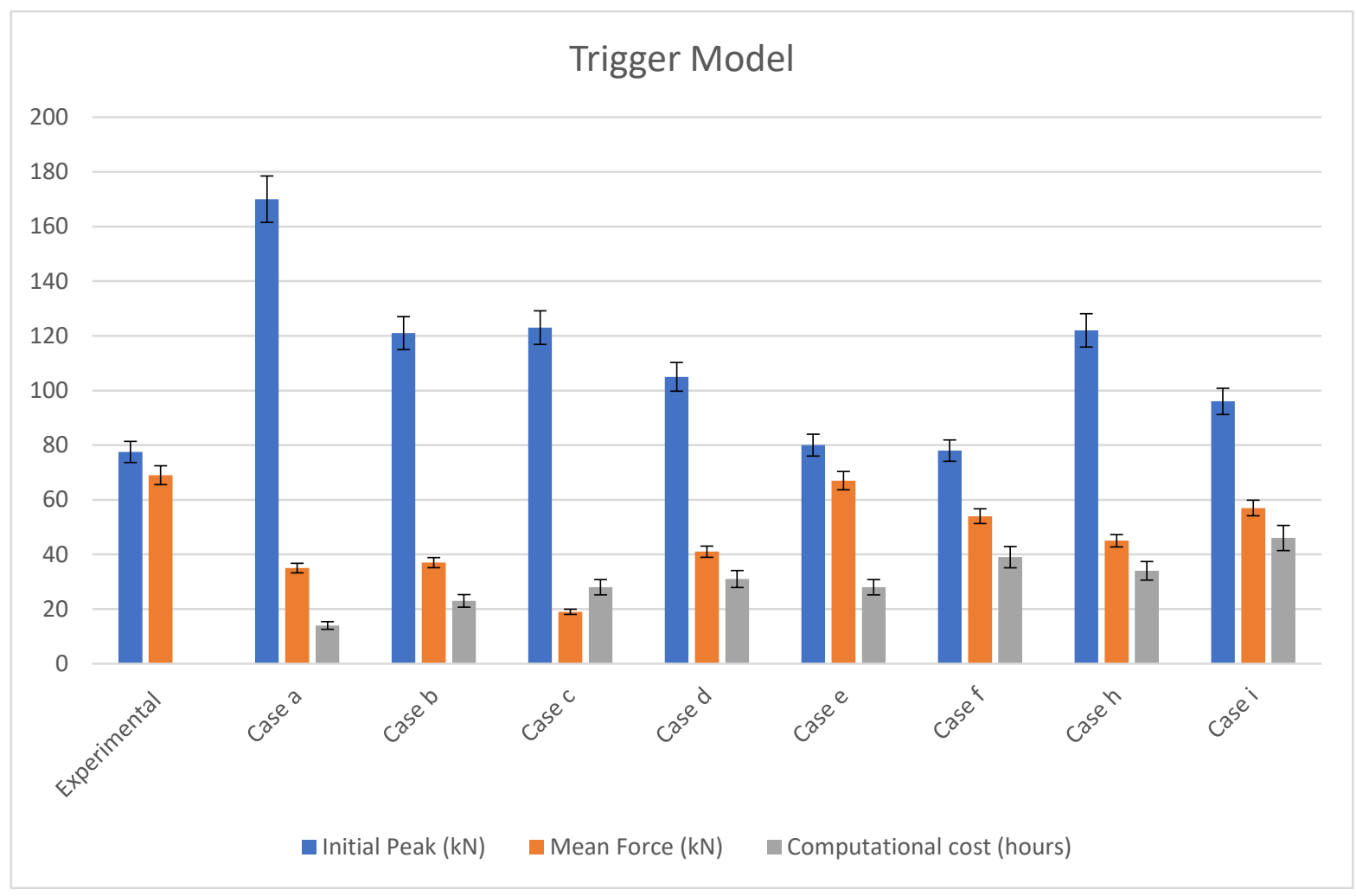

Figure 9. Trigger model comparison [66].

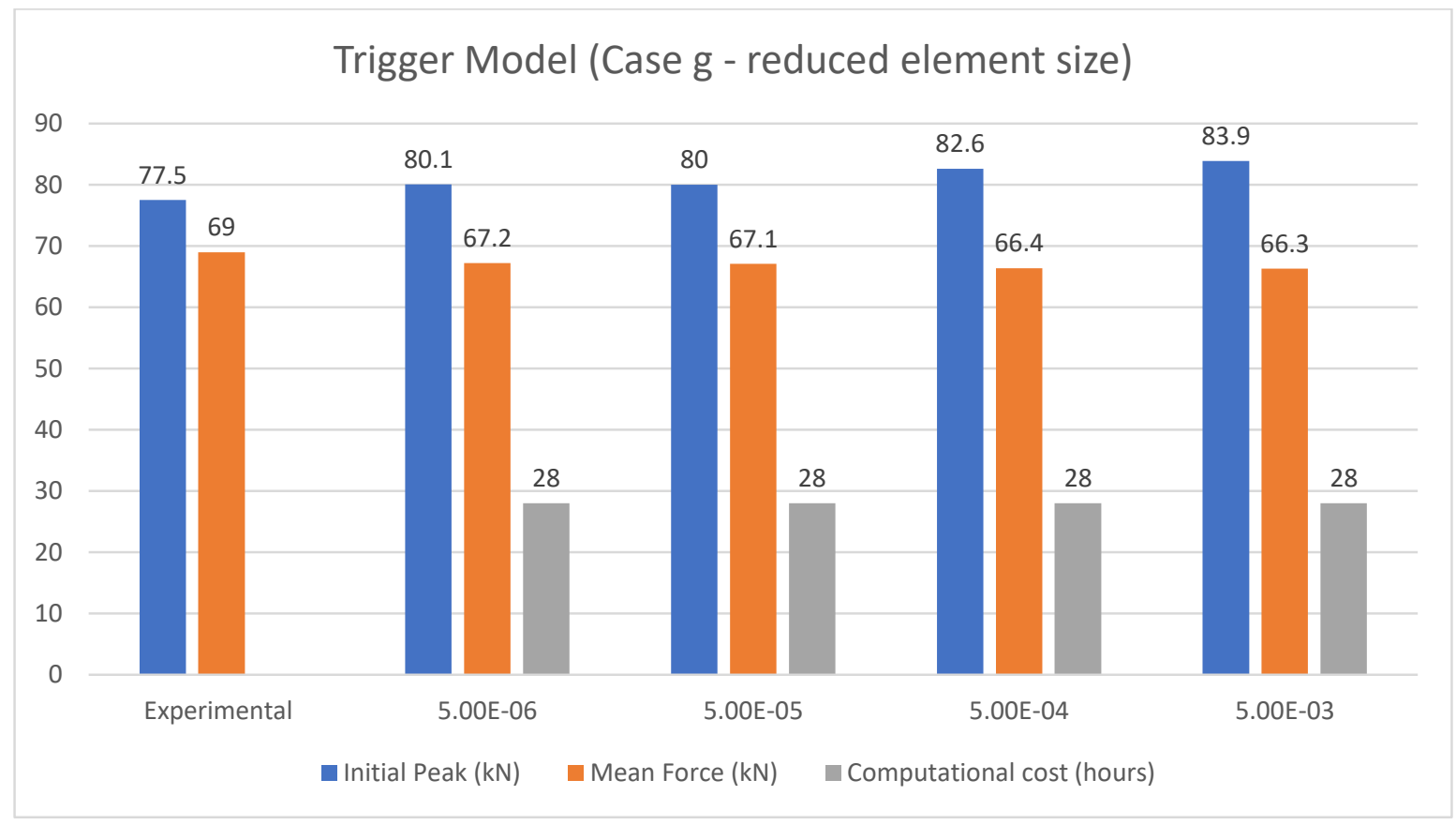

Figure 10. Trigger model case (g) comparison [66]. 


\subsection{Number of Shell(s) Configuration}

The effect of the number of shells on the energy absorption prediction of FEM is investigated. The case studies are 1, 2, 3, 4, 6, and 12 shells (see Figure 11).
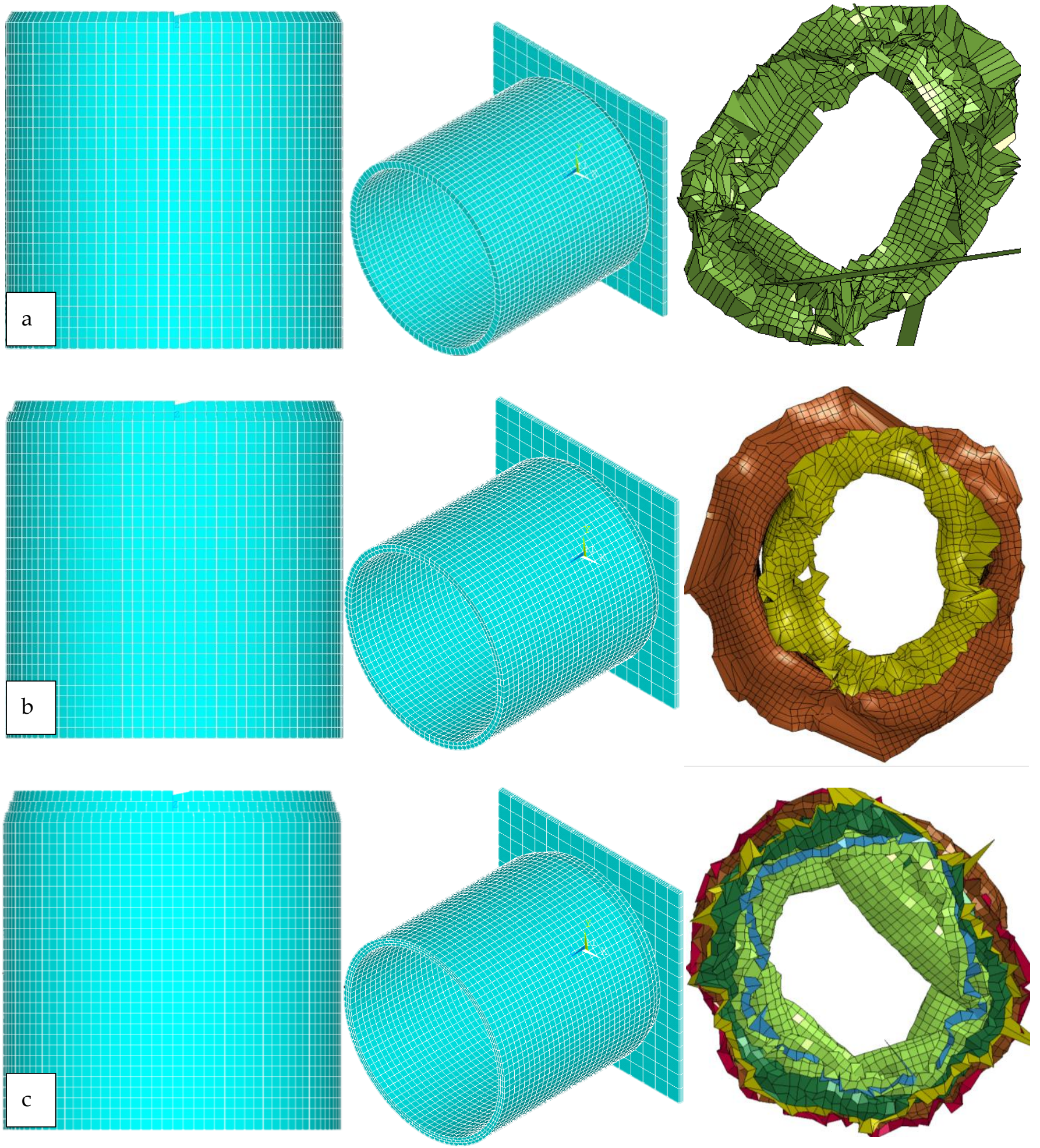

Figure 11. Cont. 

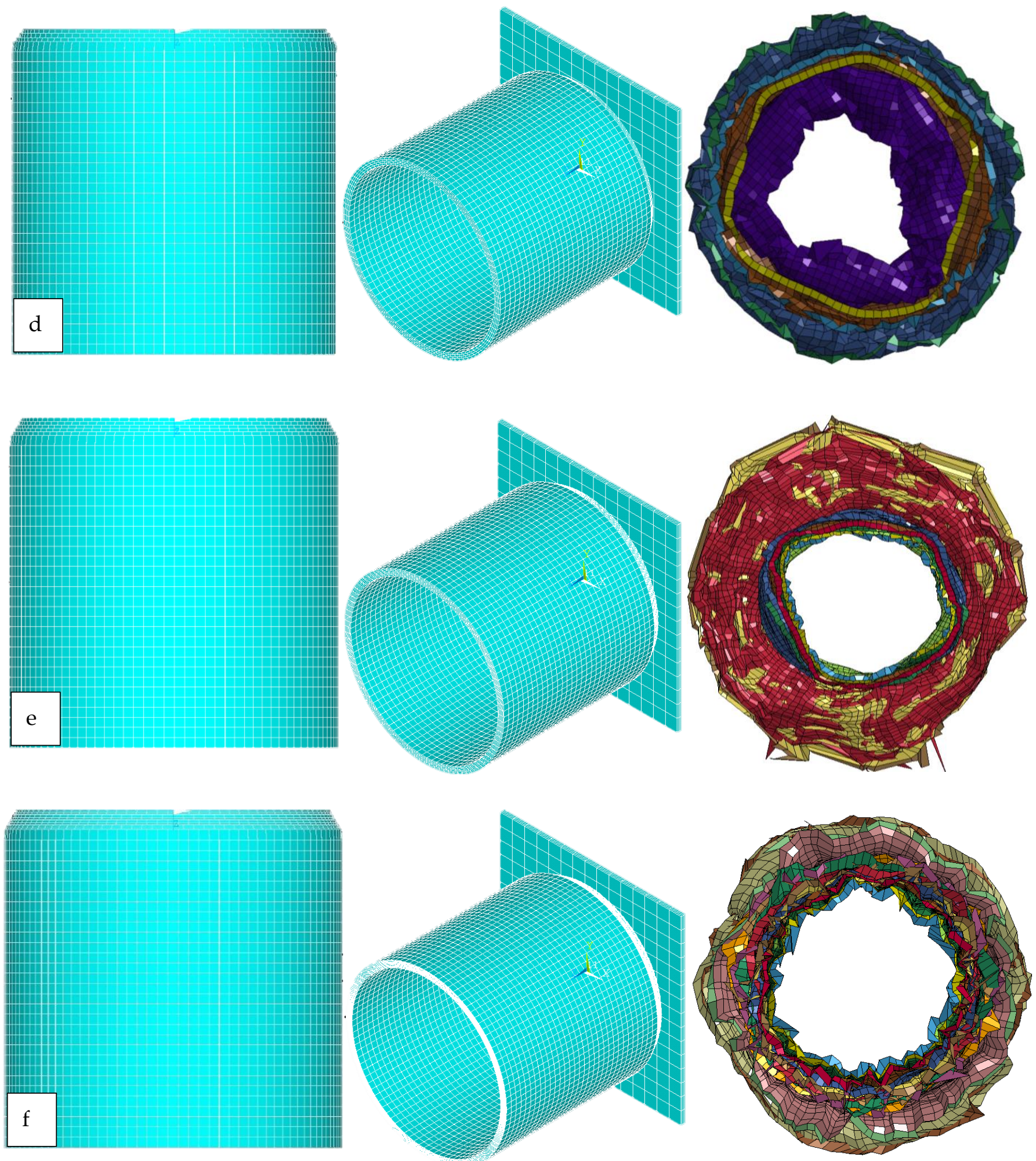

Figure 11. Number of shell configurations, (a) 1 shell, (b) 2 shells, (c) 3 shells, (d) 4 shells, (e) 6 shells, (f) 12 shells [65].

In this study, the crushed morphology is one of the factors that is greatly influenced, as seen in Figure 11. From the crushed morphology point of view, it can be concluded that, as the number of shells increase, the symmetricity and prediction of crushing behaviour improves. Since 12 plies were used in experimental studies, six cases were considered. All cases were subjected to the same trigger mechanism and applied energy. 
In Figure 12, the shell configurations are compared. In single-shell configuration, the initial peak and mean crushing force is off by $45 \%$. However, in double-shell configuration, this improves to a $5 \%$ difference. The initial peak value is $80 \mathrm{kN}$ with a crushing force of $67 \mathrm{kN}$. Hereafter, the computational cost is the deciding parameter. Since the crushing behaviour slightly or minimally improves by adding more shells. This improvement is in both the initial peak value and mean crushing force value. However, the computational cost increases rapidly by adding more shells to the model. Using the 12 shell configuration compared with experimental data, it has a $1.5 \%$ difference, and using a double-shell configuration, it has a $5 \%$ difference. From an engineering point of view, this compromising $3.5 \%$ results in solving the problem with 4.5 times less computational costs; one takes $28 \mathrm{~h}$ to converge and the other $123 \mathrm{~h}$.

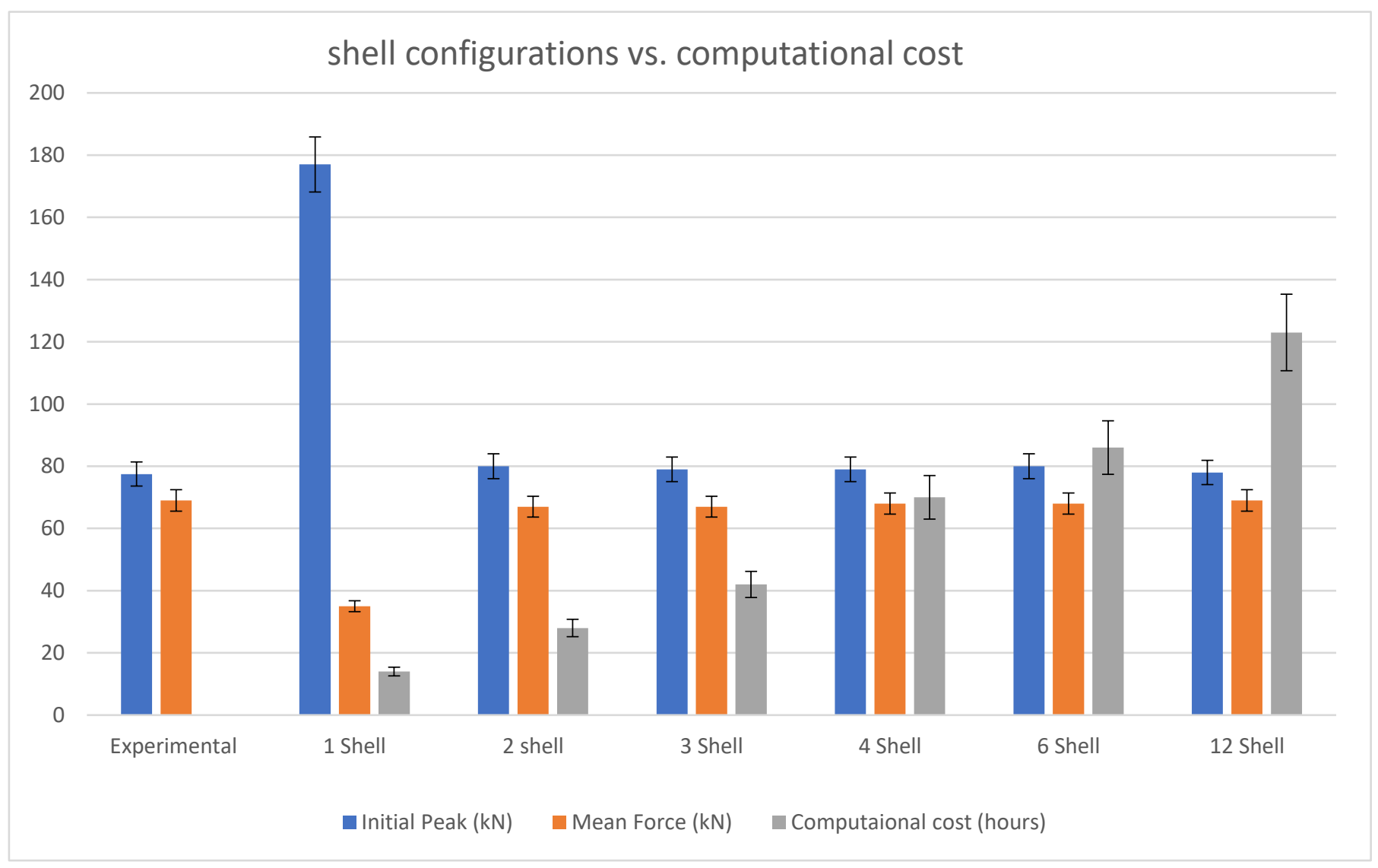

Figure 12. Shell configuration comparison [65].

At this stage, since the main concentration is energy absorption capability, the reliable and cheaper computational cost of double-shell configuration is considered in this study and is also supported by $[43,54,59,60]$.

\section{Model Sensitivity to Physical Parameters}

A robust finite element model needs to tolerate small variations in modelling parameters and be able to capture the differences. The aim of this section is to carry out a study of stability and sensitivity with respect to the material parameters, delamination, friction and impact loading. The reference model is the one developed earlier in this section and tweaking the parameters by $\pm 10 \%$.

\subsection{Material Model}

The following parameters from Mat_54-55 in LS-DYNA have been studied: stiffness, compressive strength, strain to failure in compression and strain to failure in tension. The 
stiffness and strength have an influence on fibre and matrix arrangements, and the strain to failure is a parameter that influences the experimental energy absorbed per unit of crushed volume/mass. The developed model will be compared with the experimental data. The SEA value from the experimental and numerical data should be around the error percentage, which is $5 \%$.

\subsubsection{Laminate Stiffness}

In Figure 13, the comparison of laminate stiffness is shown with a change of stiffness within $\pm 10 \%$. The SEA, initial peak and average crushing force are the main concentrations of this study compared with the relevant FEM reference. It is noticeable that the computational cost remained the same with minimal change in all cases. The influence of stiffness on crushing behaviour is illustrated in the results. A 10\% increase resulted in an increase in the initial peak value by $3 \mathrm{kN}$, the mean crushing force increased to $71 \mathrm{kN}$, and the SEA value increased by $4 \mathrm{~kJ} / \mathrm{kg}$. The displacement value was affected by a drop of $2 \mathrm{~mm}$. A $10 \%$ decrease resulted in a reduction in initial peak value by $2.2 \mathrm{kN}$, the mean crushing force decreased to $63 \mathrm{kN}$, and the SEA value dropped by $12 \mathrm{~kJ} / \mathrm{kg}$. The displacement value was affected by an increase of $6 \mathrm{~mm}$.

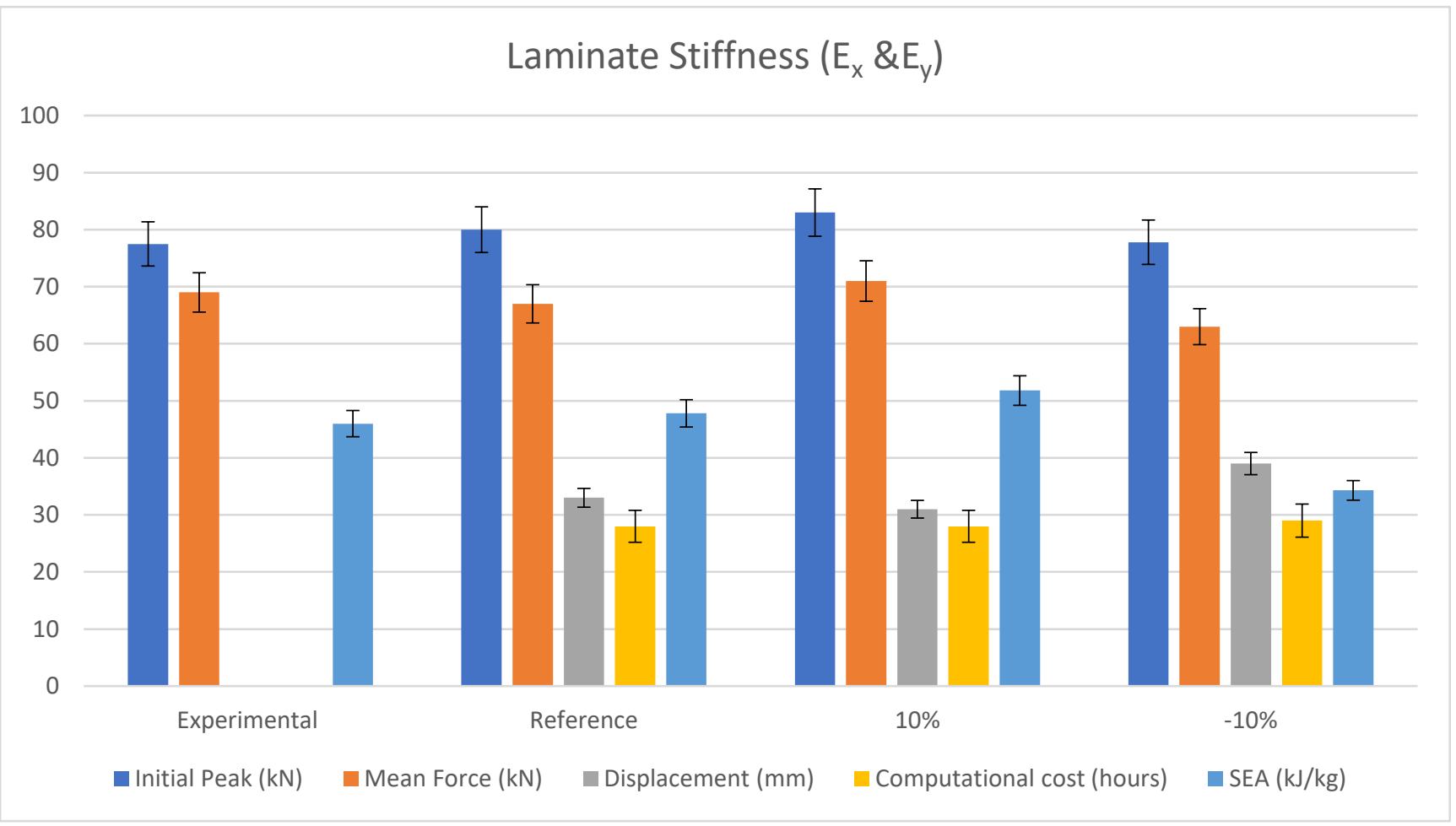

Figure 13. Laminate stiffness comparison [66].

The results showed that an increase in laminate stiffness caused a higher initial peak value and mean crushing force value. Vice versa, the reduction in laminate stiffness caused a reduction in these values, which shows the model is responsive to small changes in the parameters.

\subsubsection{Compressive Strength}

Regarding energy abruption capability in the Mat_54-55 card, compressive strength plays an important role. Figure 14 shows the comparison between compressive strength with an increase and reduction of $\pm 10 \%$. The SEA, initial peak and average crushing force is the main concentration of this study, compared with reference FEM. The computational cost remained the same with minimal changes in all cases. Increasing compressive strength 
results in an increase in initial peak value by $6.5 \mathrm{kN}$, an increase in mean crush force by $4 \mathrm{kN}$, a reduction in displacement by $3 \mathrm{~mm}$, and an increase in SEA value by $2 \mathrm{~kJ} / \mathrm{kg}$. A reduction in compressive strength by $10 \%$ results in a reduction in initial peak force value by $3 \mathrm{kN}$, a reduction in mean crushing force by $1 \mathrm{kN}$, an increase in displacement by $1 \mathrm{~mm}$, and a reduction in SEA value by $3 \mathrm{~kJ} / \mathrm{kg}$.

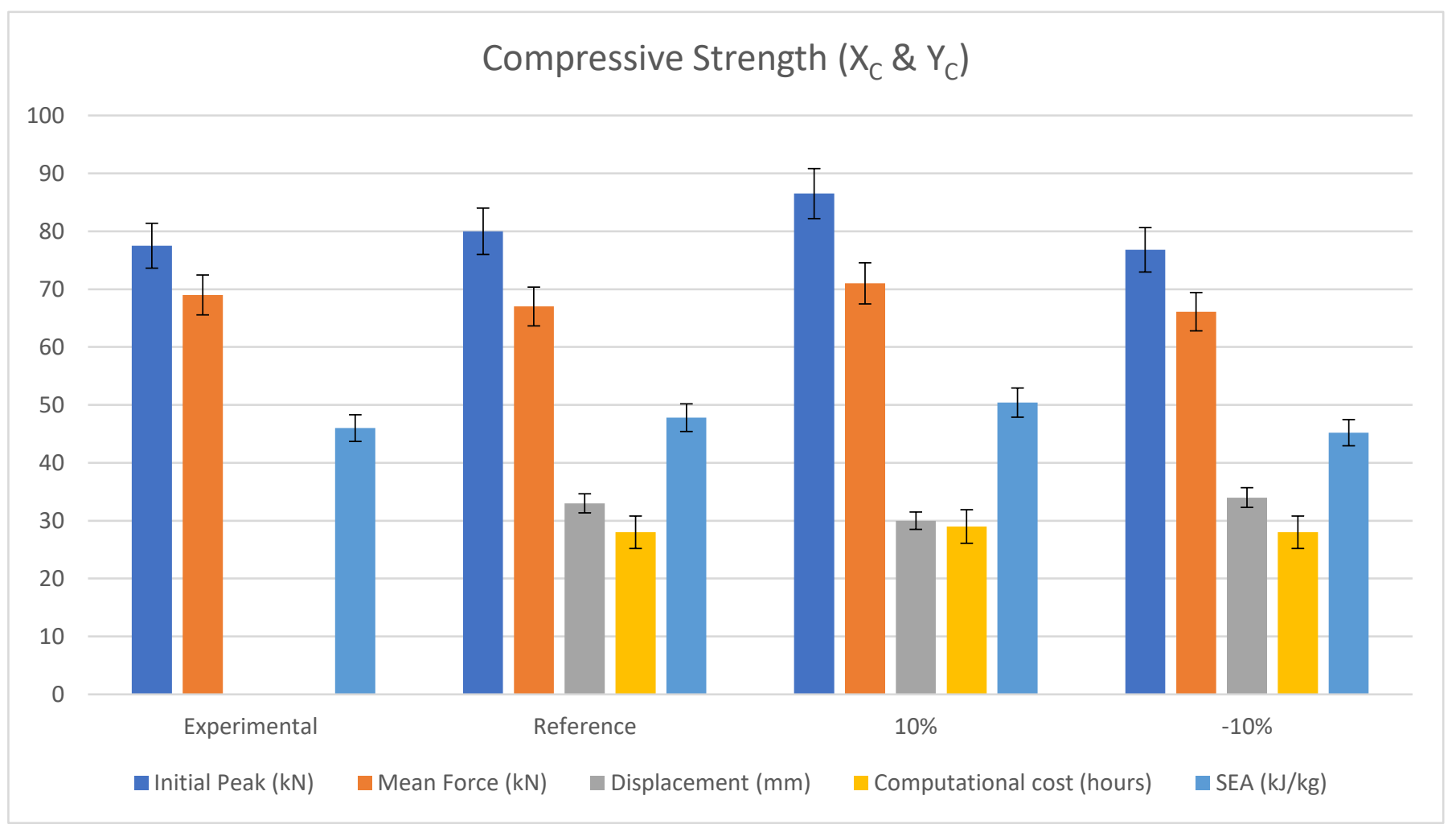

Figure 14. Compressive strength comparison [66].

The results showed that a reduction in compressive strength caused the mean crushing force value to drop along with the initial peak value.

\subsubsection{Strain to Failure}

The strain determines the element deletion, which is an important parameter for adjusting the model with experimental results. Mat_45-55 allows defining different failure strains for shear and tension/compression. The model response is governed by the deletion of elements, as previously mentioned. The failure of the elements is mainly affected by the strain to failure in compression (DFAILC) and failure in tension (DFAILT) that have been analysed by the increase and reduction of $\pm 10 \%$ of these parameters.

\section{Strain to Failure in Compression}

In Figure 15, an important influence of the failure strain in compression with an increase and reduction of $\pm 10 \%$ on the crushing efficiency is shown. The effect of a $10 \%$ increase in DFAILC results in an increase in the mean crush force of $6 \mathrm{kN}$. The initial peak was not affected, the displacement decreased by $4 \mathrm{~mm}$, and the SEA value increased to $53.7 \mathrm{~kJ} / \mathrm{kg}$, with a $6 \mathrm{~kJ} / \mathrm{kg}$ difference in comparison to the reference model. The effect of a $10 \%$ drop in DFAILC results in a drop in mean crushing force value by $5 \mathrm{kN}$, an increase in displacement by $7 \mathrm{~mm}$, and a $10 \mathrm{~kJ} / \mathrm{kg}$ drop in SEA value. 


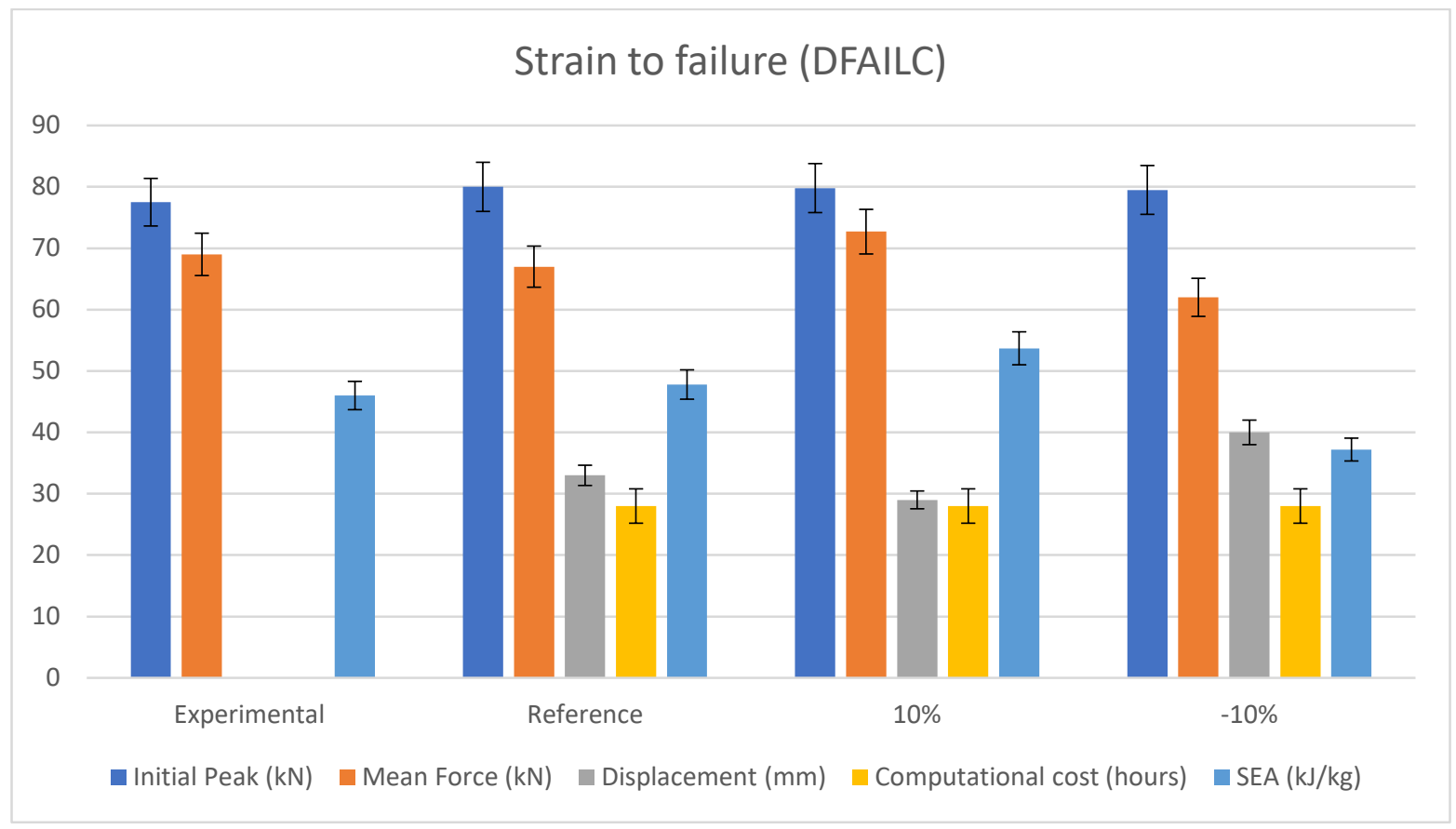

Figure 15. Strain to failure in compression (DFAILC) [66].

Strain to Failure in Tension

In Figure 16, an important influence of the failure strain in tension with increase and reduction of $\pm 10 \%$ on the crushing efficiency is shown. The effect of a $10 \%$ increase in DFAILT results in an increase in mean crush force of $5 \mathrm{kN}$, an initial peak increase of $2 \mathrm{kN}$, a displacement decrease of $2 \mathrm{~mm}$ and a SEA value increase of $55 \mathrm{~kJ} / \mathrm{kg}$, with a $7 \mathrm{~kJ} / \mathrm{kg}$ difference in comparison to the reference model. The effect of a $10 \%$ drop in DFAILT results in a drop in mean crushing force value of $2 \mathrm{kN}$, an increase in initial peak value by $5 \mathrm{kN}$, an increase in displacement by $2 \mathrm{~mm}$, and a $3 \mathrm{~kJ} / \mathrm{kg}$ drop in SEA value.

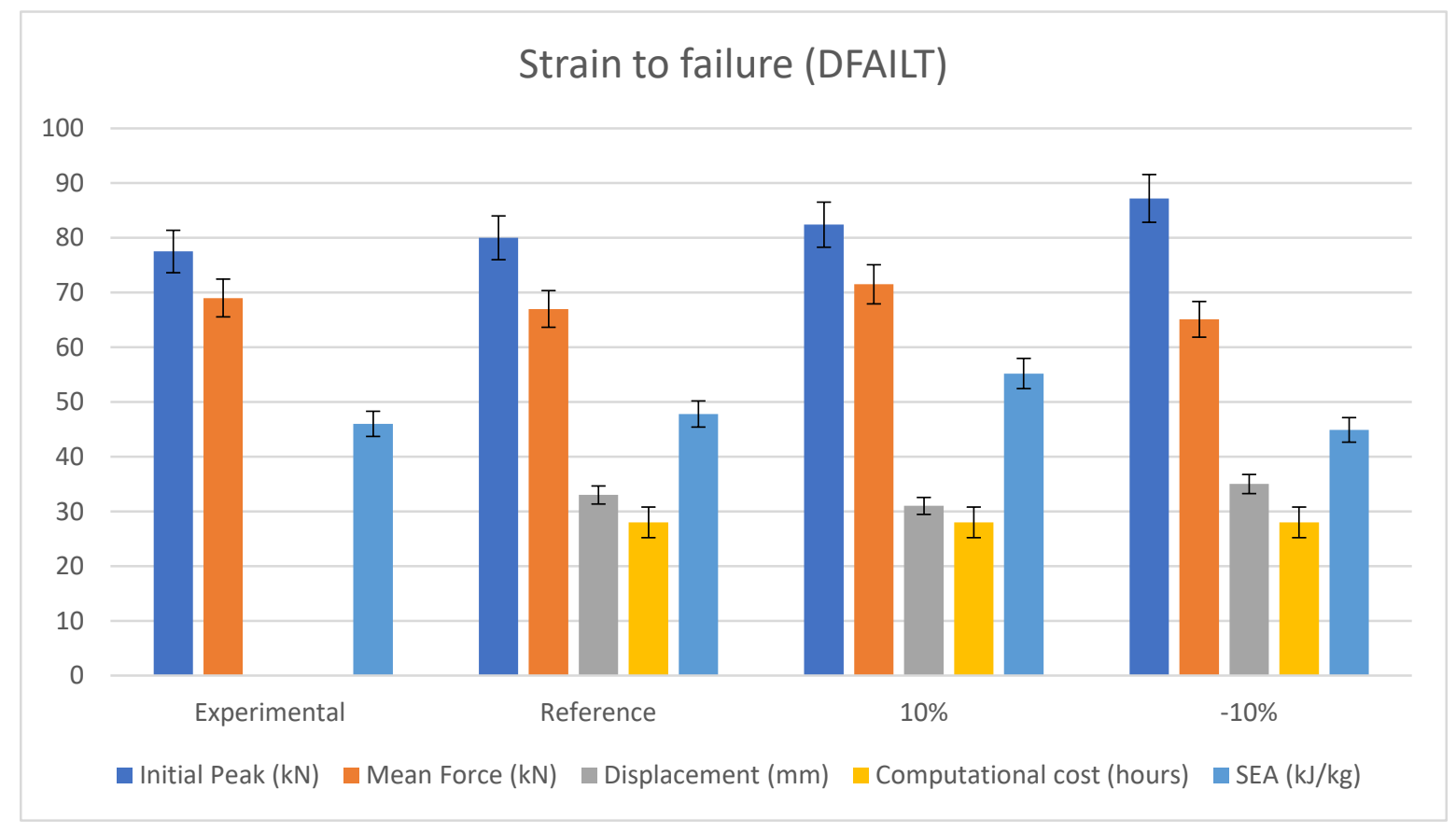

Figure 16. Strain to failure in tension (DFAILT) [66]. 


\subsection{Delamination Model}

The delamination between the shell was modelled with tiebreak option 8 described in Sections 2.2 and 4.1 in detail. The current study in this section is to determine the element size and the sensitivity of the delamination algorithms according to Table 2 . To ensure the mesh is fine enough to avoid premature failure of the interface and instability, the model sensitivity towards the energy release rate will be analysed.

\subsubsection{Tiebreak Contact Element Size Sensitivity}

To capture the debonding of the plies, a simple model was created to simulate a DCB test for a Mode-I delamination test. Different mesh sizes were considered: $1.5 \times 1.5 \mathrm{~mm}$, $2.5 \times 2.5 \mathrm{~mm}$ and $3.5 \times 3.5 \mathrm{~mm}$ (see Figures 17 and 18).

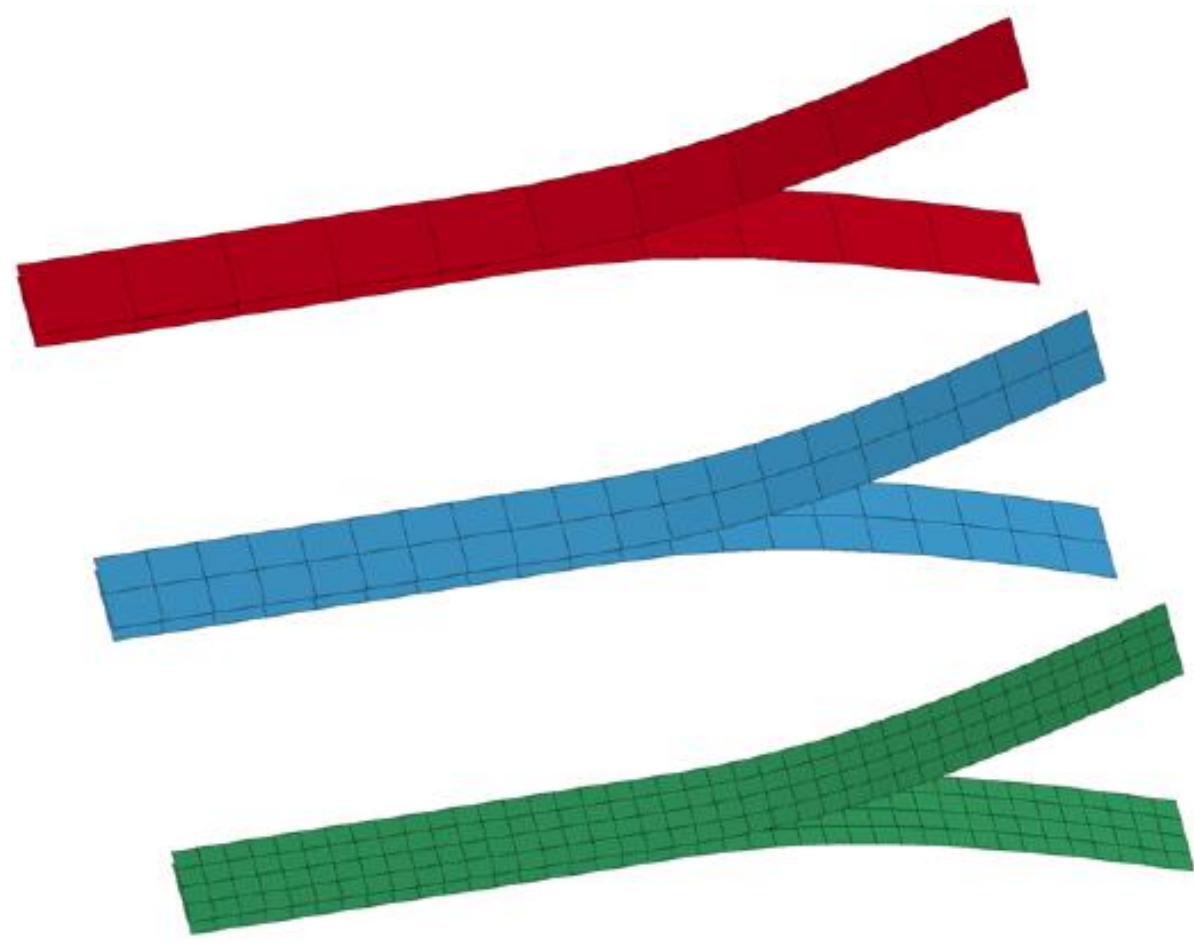

Figure 17. Tiebreak contact element size test [66].

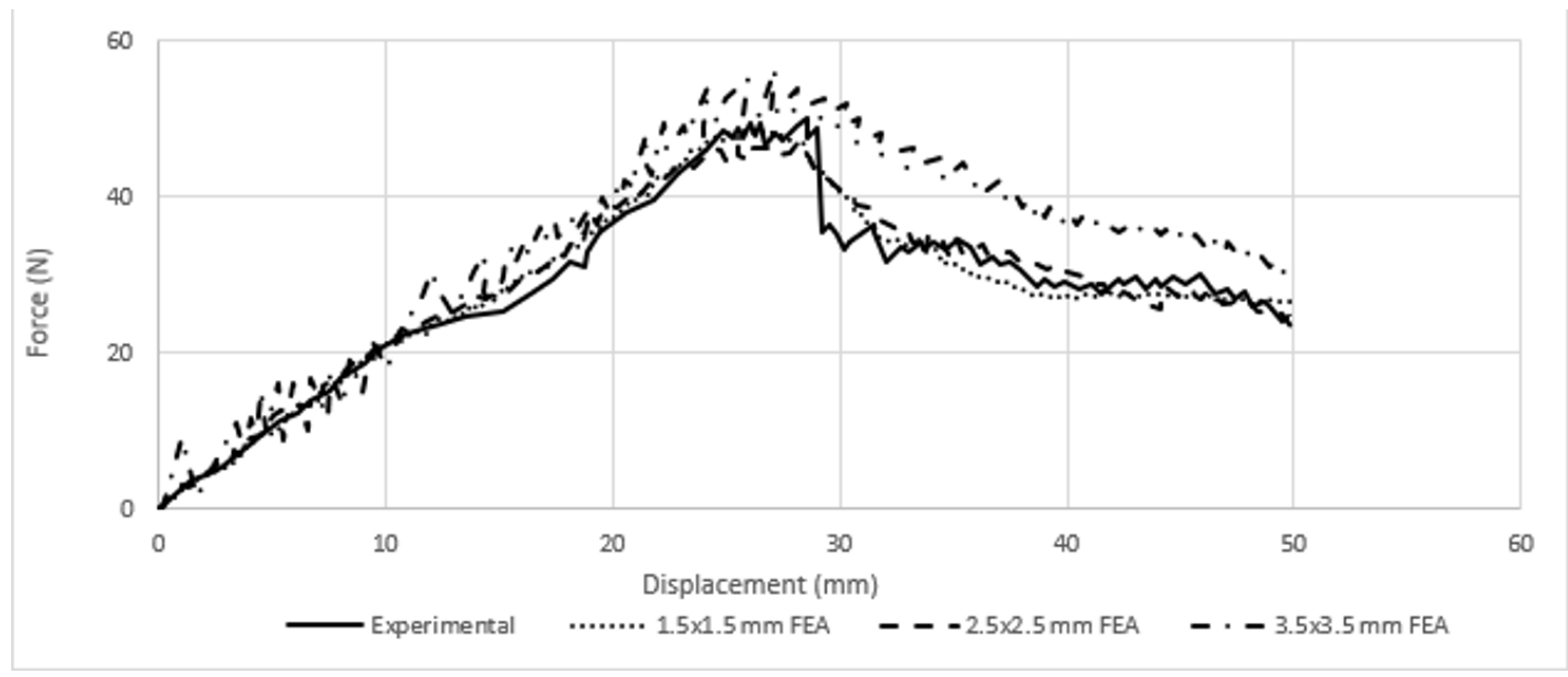

Figure 18. Force-distance curve of Mode-I delamination, experimental and FEA comparison [66]. 
To assure the obtained results would be relevant to experimental data, the FE results were compared with the experimental data. In Figure 18, all cases have captured the experimental curve; however, the $1.5 \times 1.5 \mathrm{~mm}$ and $2.5 \times 2.5 \mathrm{~mm}$ element sizes have closer values with minimal differences. The element size of $3.5 \times 3.5 \mathrm{~mm}$ overestimated the results throughout, and $2.5 \times 2.5 \mathrm{~mm}$, which is the element size (see Section 4.5.), was concluded to be both accurate enough and computationally cost-efficient.

\subsubsection{Delamination Resistance}

The aim of this study is to examine the sensitivity and the importance of the effect of the tiebreak contact PARAM function on the energy absorption capability of the developed FEM. Once the progressive failure has been established, the debonding of the plies is ruled purely by normal stress, and according to Equation (13), the $G_{C I}$ is governed by normal stress and PARAM from the contact card. An increase in PARAM, therefore, results in an increase in $G_{C I}$ proportionally. This method has been used in this study to analyse its effect on Mode-I delamination resistance.

Figure 19 illustrates the effect of this phenomenon on crushing behaviour and energy absorption capability of the FEM by an increase and reduction of $\pm 10 \%$. The effect of a $10 \%$ increase in $G_{C I}$ results in an increase in mean crush force by $6 \mathrm{kN}$, no change in initial peak, a displacement decrease of $5 \mathrm{~mm}$ and a SEA value increase of $54.5 \mathrm{~kJ} / \mathrm{kg}$, with a $6 \mathrm{~kJ} / \mathrm{kg}$ difference in comparison to the reference model. The effect of a $10 \%$ decrease in $G_{C I}$ results in a drop in mean crushing force value of $6 \mathrm{kN}$, no change in initial peak value, an increase in displacement of $7 \mathrm{~mm}$, and a $5.5 \mathrm{~kJ} / \mathrm{kg}$ drop in SEA value.

\section{Delamination (Energy release rate)}

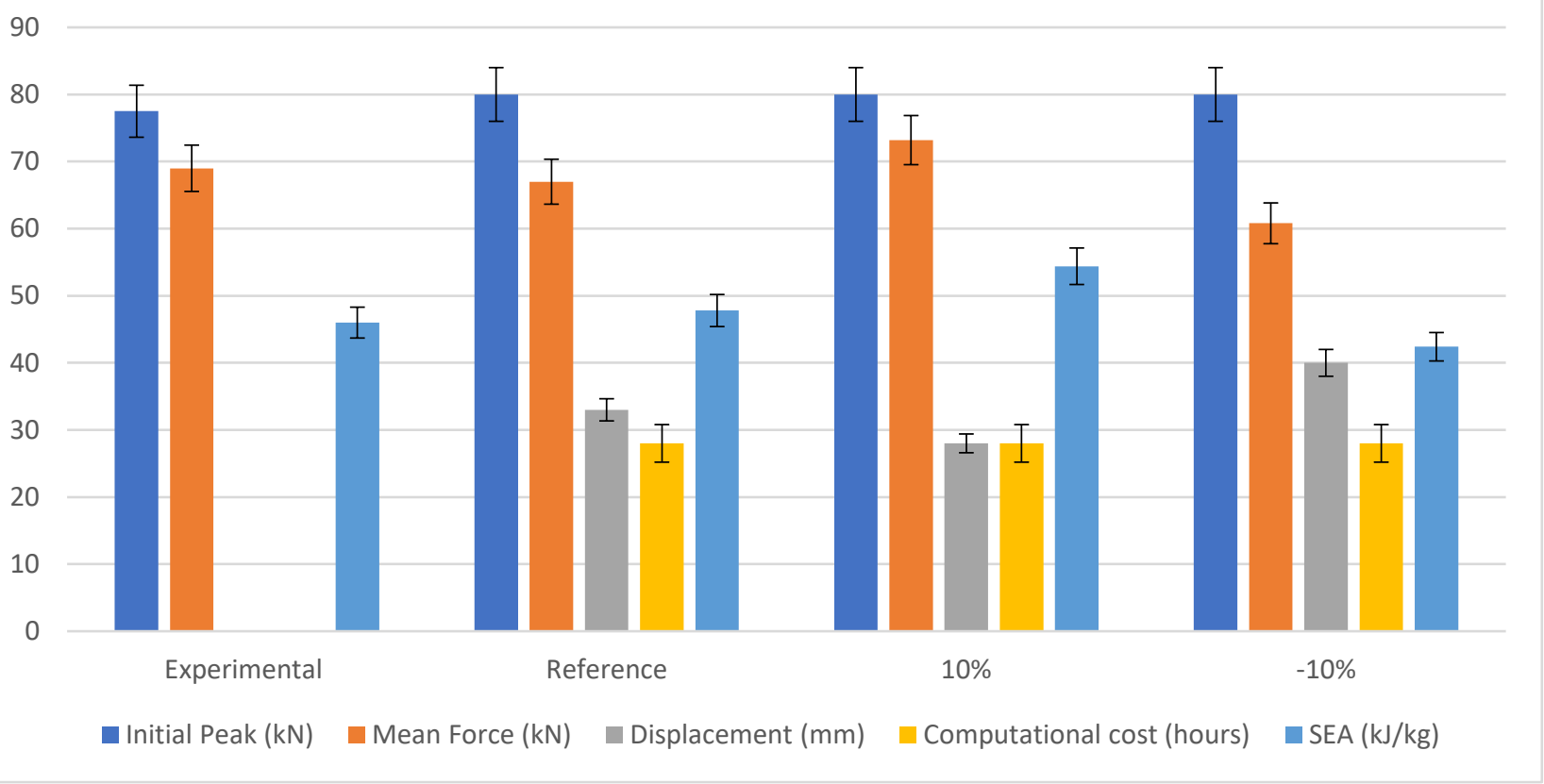

Figure 19. Delamination resistance comparison [66].

The results indicate that the Mode-I energy release rate has an important influence on the energy absorption capability, mean crushing force value, displacement and SEA value. To conclude this, it can be noted that modelling delamination as tiebreak option 8 has been established to be sensitive towards capturing and affecting Mode-I delamination. The input parameters have a major effect on delamination resistance. Therefore, it is essential to validate Tiebreak input parameters as it has been carried out in previous sections (see Sections 2.2, 4.1 and 5.2.1). 


\subsection{Friction}

The coefficient of friction is one of the physical parameters that influences the progression of the simulation. In the literature, many values have been stated, varying from 0.1 to 0.3 for static and 0.1 to 0.2 for dynamic. The chosen values for static friction coefficient is 0.3 and 0.2 for the dynamic friction coefficient $[3-7,43,53,59,60]$. Both impactor to inner shell and inner shell to outer shell friction coefficients are set to 0.3 and 0.2 for static and dynamic, respectively. This is based on trial and error and based on previous researchers $[3-7,43,53,59,60]$. This combination enables a sensitive crushing performance. In this study, the sensitivity of the FEM to friction is studied. The two scenarios are the friction between the impactor and the inner shell and the friction between the shells.

\subsubsection{Impactor to Shell}

In Figure 20, the results from the friction between the impactor and the inner shell are compared based on an increase and decrease of $\pm 10 \%$. The influence of cthe oefficient of friction on mean crushing force is 2.5 and $-3.5 \mathrm{kN}$. The only parameter that is not influenced by friction is computational cost. The initial peak force increased by $0.5 \mathrm{kN}$, which is minimal and small enough to neglect when increased by $10 \%$ and no change with $10 \%$ reduction. The main concentration was mean crushing force, displacement and SEA. With a $10 \%$ increase, the mean crushing force increased by $2.5 \mathrm{kN}$, the displacement dropped by $2 \mathrm{~mm}$, and the SEA value increased by $3 \mathrm{~kJ} / \mathrm{kg}$. By decreasing the friction by $10 \%$, the initial peak had no effect, the mean crushing force dropped by $3.5 \mathrm{kN}$, the displacement increased by $2 \mathrm{~mm}$, and the specific energy absorption decreased to $45.3 \mathrm{~kJ} / \mathrm{kg}$, which is around $2.5 \mathrm{~kJ} / \mathrm{kg}$. This parameter can influence the energy absorption capability, and based on the literature, the optimum value is 0.3 and 0.2 for static and dynamic, respectively [59,60].

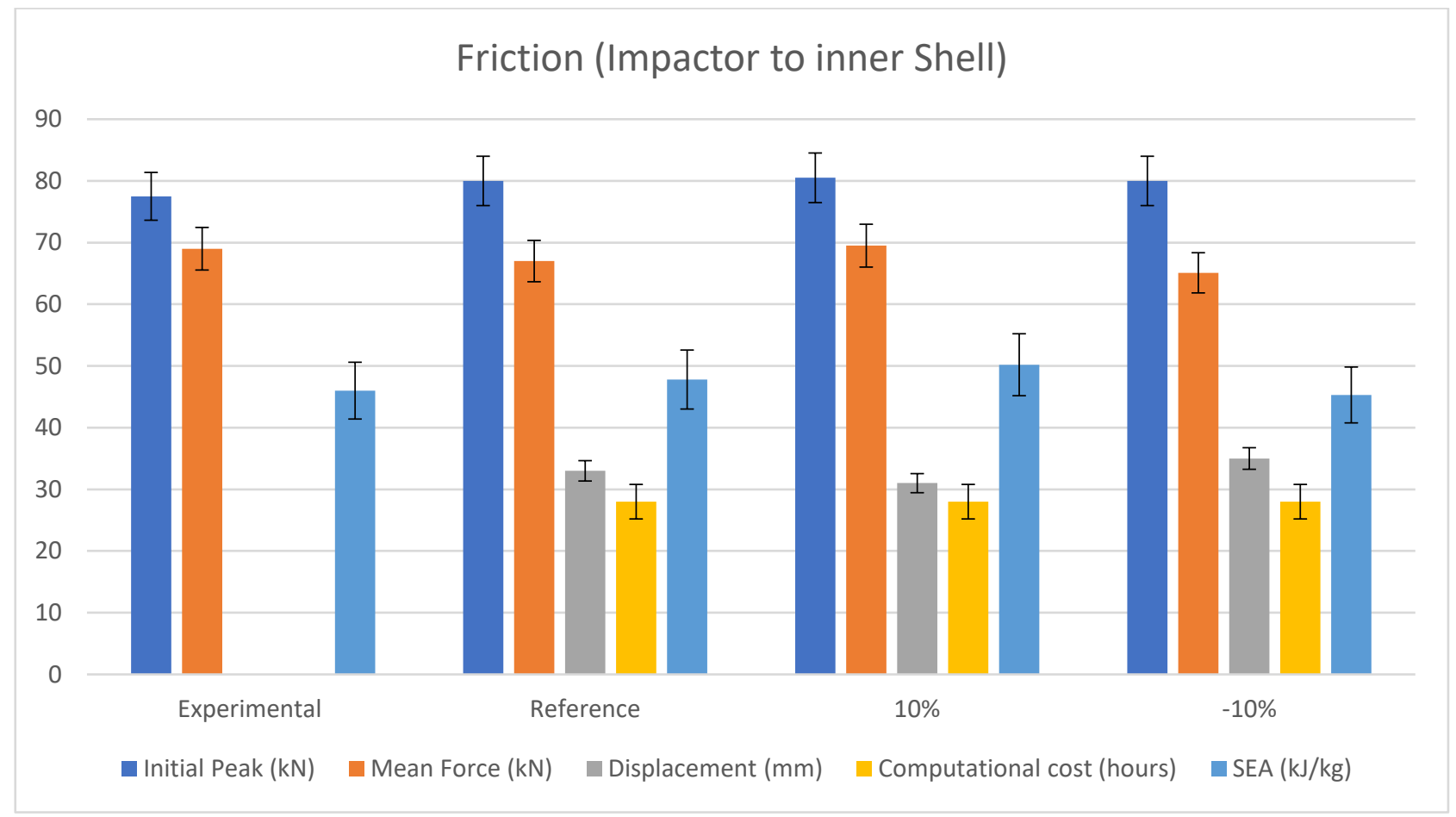

Figure 20. Impactor to inner-shell friction coefficient comparison [66].

\subsubsection{Shell to Shell}

Many researchers have used friction to simulate delamination, e.g., [59,60]. Friction influences the energy absorption capability. However, using friction influences the SEA value, increases friction between the shells, and causes a higher SEA value, and this 
compared with experimental data cannot be considered as a correct FEM, as the SEA comparison from the experimental and numerical data would be more than the error percentage. Friction influences the mean crush force and, consequently, affects SEA value. Due to this, a different approach was considered. Tiebreak option 8 was utilised instead of friction to model delamination as this contact card can define the Mode-I and Mode-II energy release rate, which simulates delamination. However, the correct friction between the shells must be implemented. This friction between the plies also exists in real scenarios, and its effect on the energy absorption capability must be addressed.

In Figure 21, the results from friction between the inner shell and the outer shell are compared based on an increase and decrease of $\pm 10 \%$. The influence of the coefficient of friction on mean crushing force is 3 and $-3.5 \mathrm{kN}$. Throughout the study, the computational cost and initial peak force was unaffected. The main concentration was mean crushing force, displacement and SEA. With a $10 \%$ increase, the mean crushing force increased by $3 \mathrm{kN}$, the displacement dropped by $1 \mathrm{~mm}$, and SEA value increased by $3.5 \mathrm{~kJ} / \mathrm{kg}$. By decreasing the friction by $10 \%$, the initial peak had no effect, the mean crushing force dropped by $3.5 \mathrm{kN}$, the displacement increased by $3 \mathrm{~mm}$, and the specific energy absorption decreased to $41.8 \mathrm{~kJ} / \mathrm{kg}$, which is around $6.5 \mathrm{~kJ} / \mathrm{kg}$. This parameter can influence the energy absorption capability, and based on the literature, the optimum value is 0.3 and 0.2 for static and dynamic, respectively $[59,60]$.

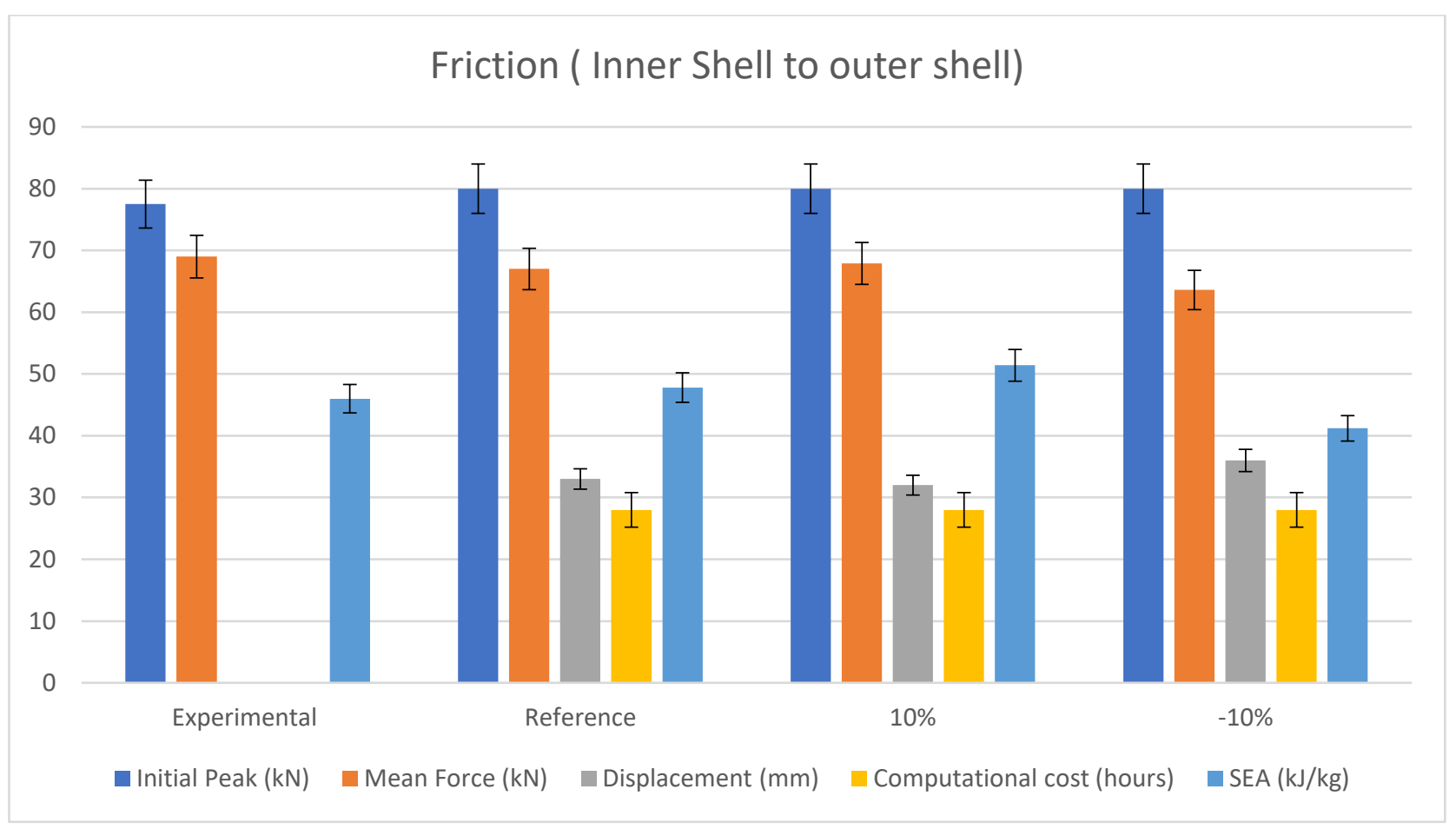

Figure 21. Inner-shell to outer-shell friction coefficient comparison [66].

\subsection{Impact Velocity}

In this section, various impact velocities are raised to study and analyse the developed model against its sensitivity towards capturing the initial peak, mean crush force, displacement (stroke) and specific energy absorption. In this study, the experimental data and reference model are compared with different impact velocities and applied kinetic energies. The cases are $4 \mathrm{~m} / \mathrm{s}(0.84 \mathrm{~kJ}), 5 \mathrm{~m} / \mathrm{s}(1.31 \mathrm{~kJ}), 6 \mathrm{~m} / \mathrm{s}(1.89 \mathrm{~kJ})$ and $8 \mathrm{~m} / \mathrm{s}(3.4 \mathrm{~kJ})$. Understanding how the model is robust with respect to the input kinetic energy would indicate the range of impact conditions predicted by the model.

Figure 22 shows the extracted results from the simulations. The simulation results illustrate a similar value or up to $0.4 \%$ difference in initial peak value, and the specific 
energy absorption, which indicates the energy absorption per crushed mass, is within $4 \%$ of the reference model. The mean crushing force is slightly affected, although the highest difference from the reference model is $3.5 \%$.

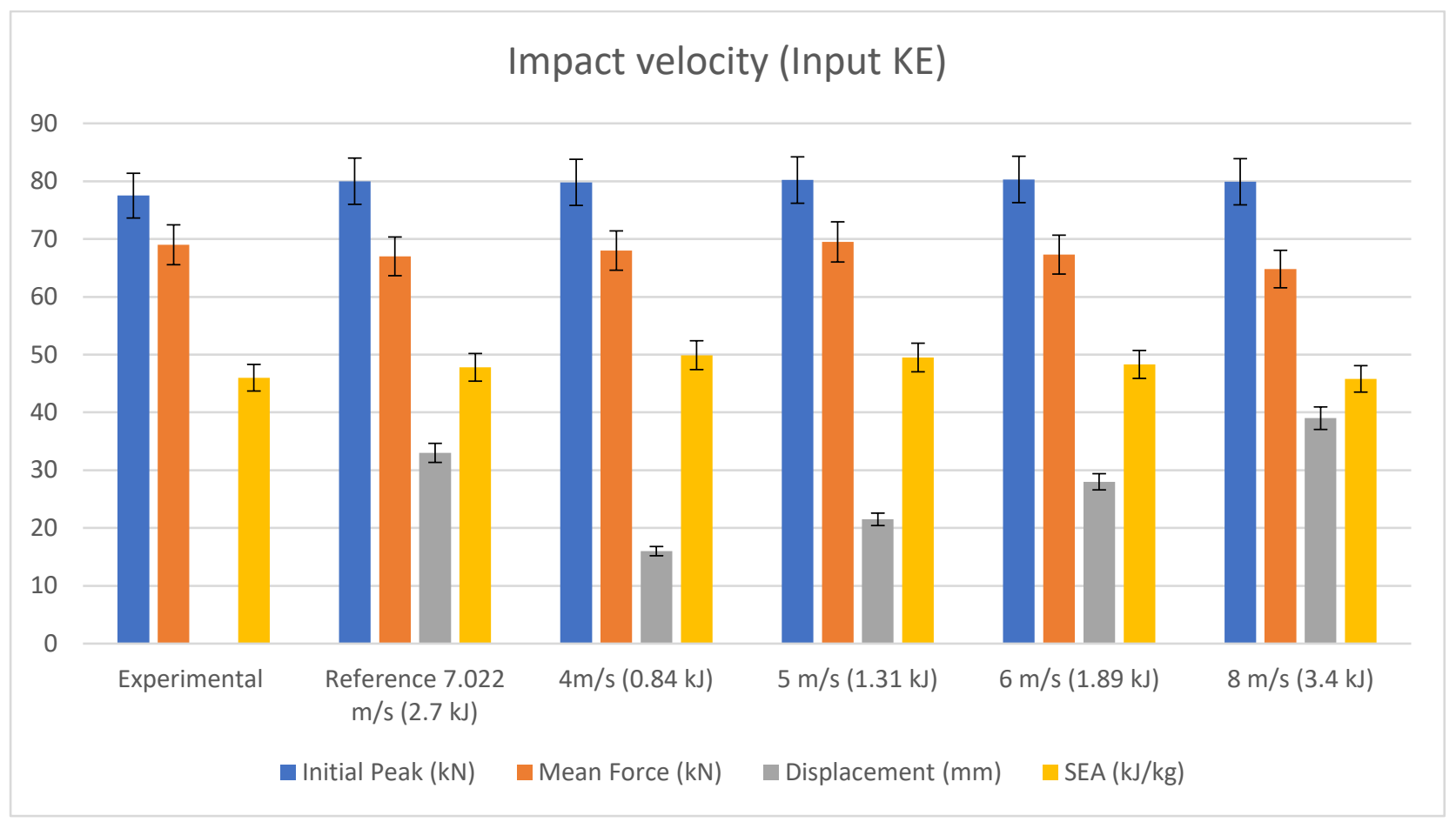

Figure 22. Impact velocity or kinetic energy input sensitivity data [66].

\section{Modelling limitations}

Based on the study carried out in Section 5, sensitivity towards physical parameters was studied based on the developed model. The FEA results are influenced by many input parameters. To develop a model that is capable of predicting energy absorption in an accurate enough format, a few extracted results must also be acceptable. These parameters are computational cost, initial peak force, mean crushing force, displacement and specific energy absorption. A relatively simple model approach leads to high efficiency, and this was the main concentration of this section. There is a balance between computational cost and final results that needs to be within an acceptable range of up to $10 \%$ [59].

In Mat_54, some parameters have no physical meaning, which means some limitations might cause the simulation model to be ruled by non-physical parameters. Therefore, the applicability of the model to another crush scenario must be carried out with care. A change in geometry and the mechanical properties mean that the model can be adapted to that specific crash scenario with care and some adjustments.

More advanced material cards are developed with solid elements to improve capturing delamination energy. Further studies are needed on the mechanical properties of the material and energy release rate in Mode-I and Mode-II. Most importantly, using solid elements rapidly increases computational costs compared with shell elements. This technique increases accuracy, although both testing and computational costs increase.

Increasing the material model complexity leads to further test data but is expensive and increases computational costs. Depending on case studies, from an engineering point of view, a finite element model with an accuracy of up to $10 \%$ is acceptable $[59,60]$. However, the developed model has its limitation in showing the fracture and crushing on a smaller scale, force-displacement characteristics, and debris wedge. 


\subsection{Fracture Morphology}

Regarding crushed morphologies, to capture axial splits using Mat_54, the DFAILM, which is the failure strain in the matrix direction [47], can be utilised. Adjusting the value of DFAILM enables matrix splitting to occur (see Figure 23), as observed in the experiments. However, this parameter influenced the computational costs to be unreasonably high. Due to this fact and keeping a reasonable experimental efficiency, DFAILM values were retracted to original values. It is worth mentioning that, in this research, the main concentration was capturing energy absorption capability. DFAILM had a marginal effect on energy absorption capability, as mentioned above. In the material model Mat_54-55, the stacking sequence plays an important part in crushed morphologies. In Figure 24, the FEM crushed morphologies of $[0]_{12}$ are shown, which resembles the experimental crushed morphologies. However, using \pm 45 leads to inadequate failure modes if DFAILM values exceed $10 \%$ to obtain matrix splitting/separation (see Figure 23b).

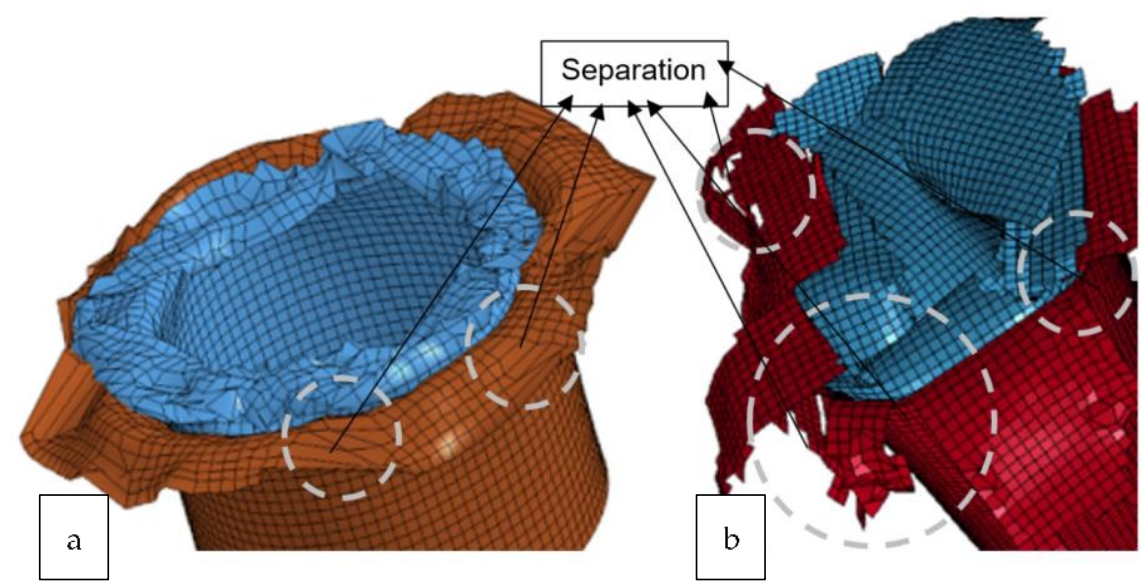

Figure 23. Effect of DFAILM on axial split, (a) reference model (b) 10\% increase DFAILM [65].

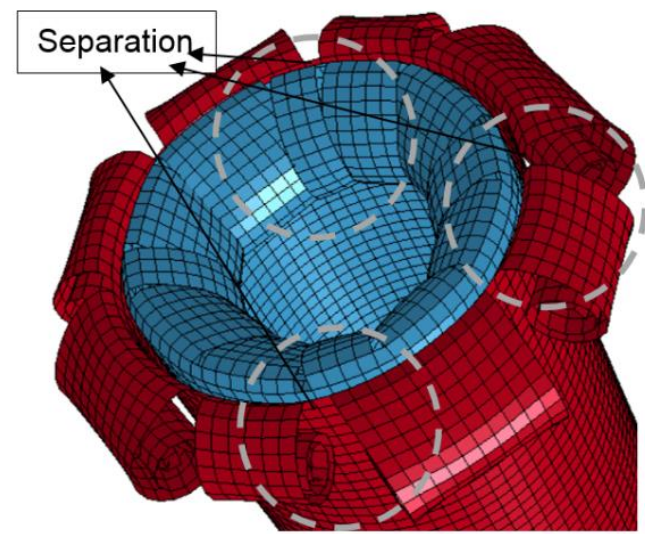

Figure 24. Effect of stacking sequence of $[0]_{12}$ configuration on petal formation of FEM crushed morphologies using DFAILM [59].

Figure 25 shows the comparison between the reference FEM and increase in DFAILM by $10 \%$ and $20 \%$. The effect of DFAILM on the axial split is shown in Figure 23 , which improves the crushed morphology representation. Although, the results regarding energy absorption capability, including SEA values, were unaffected by this parameter. At a 10\% increase, the axial split occurs in this FEM, which causes a $138 \%$ increase in computational costs. Increasing DFAILM by $20 \%$ causes a $176 \%$ increase in computational costs. 


\section{Strain to failure (DFAILM)}

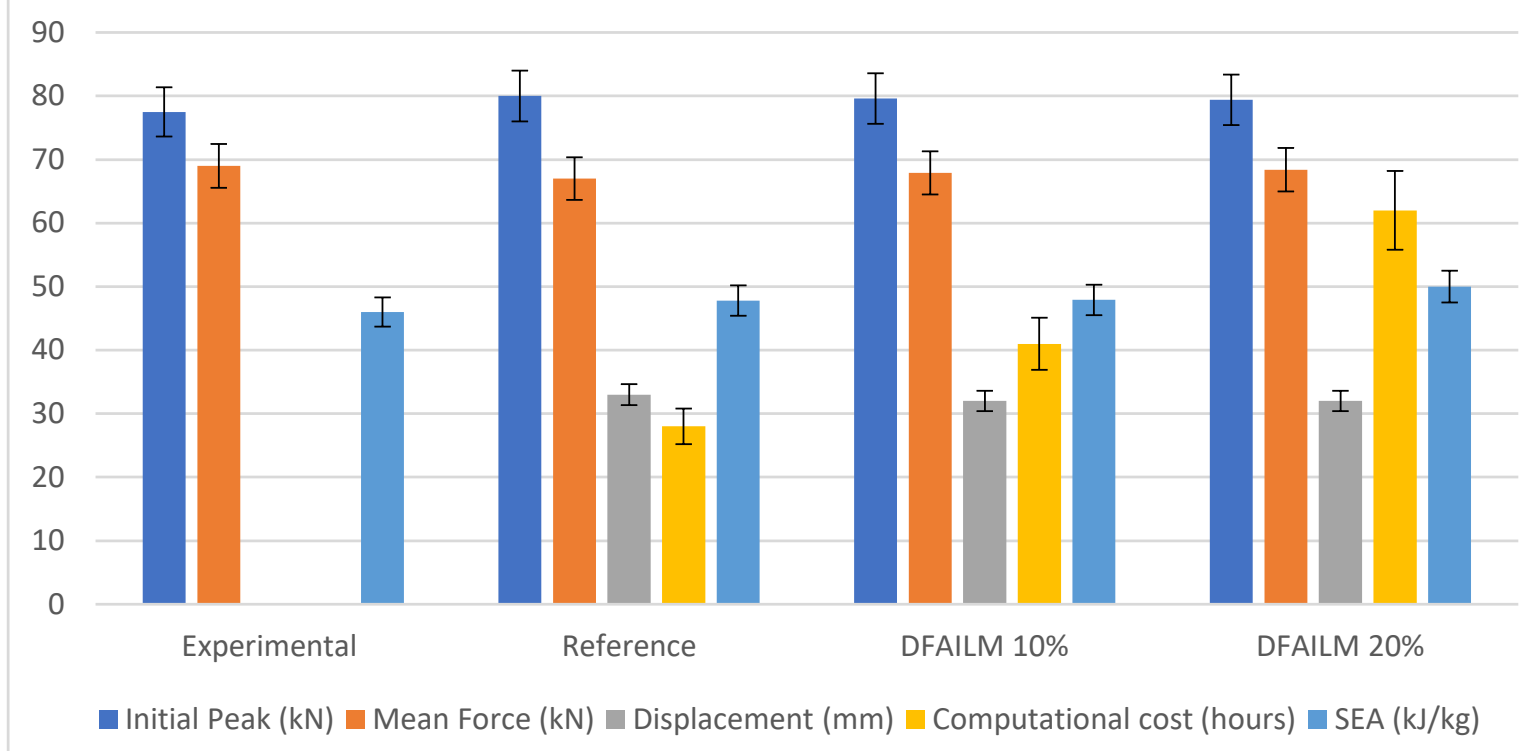

Figure 25. Strain to failure in matrix direction (DFAILM) [66].

In consideration of these results, capturing an axial split seems rather unreasonable due to its effect on computational costs. Increasing the DFAILM value by 10 to $20 \%$ had minimal or no effect on the results, and an axial split below 10\% in this FEM does not occur.

\subsection{Force-Displacement Characteristics}

The visual differences in crushed morphologies and the crushing process of composite tubes and FEA are captured by the force-displacement curve diagram. Figure 26 shows a comparison between numerical and experimental data.

As described by Hall [17], the experimental data have a serrated shape where the positive slope segments, e.g., (ab) represents the increase in resistance load due to multiple crack propagations until point (b) is reached. Further crushing is initiated, causing a negative slope or drop in resistance force.

In the finite element (dotted black), the oscillations are governed by the element deletion between fronds, and the amplitudes are a function of the strain to failure of the element controlling the tearing and the mode-I delamination resistance.

At any stage of the crushing process, the experimental resistance force is governed by the weakest possible collapse mode(s). The curves from the FEA and experiment have different amplitudes and ranges (see Figure 26). The amplitudes of the curve and wavelength of FEA are governed by element deletion, and the element size affects the wavelengths. Nevertheless, this leads to collapse modes, which are not captured by the model properly. 


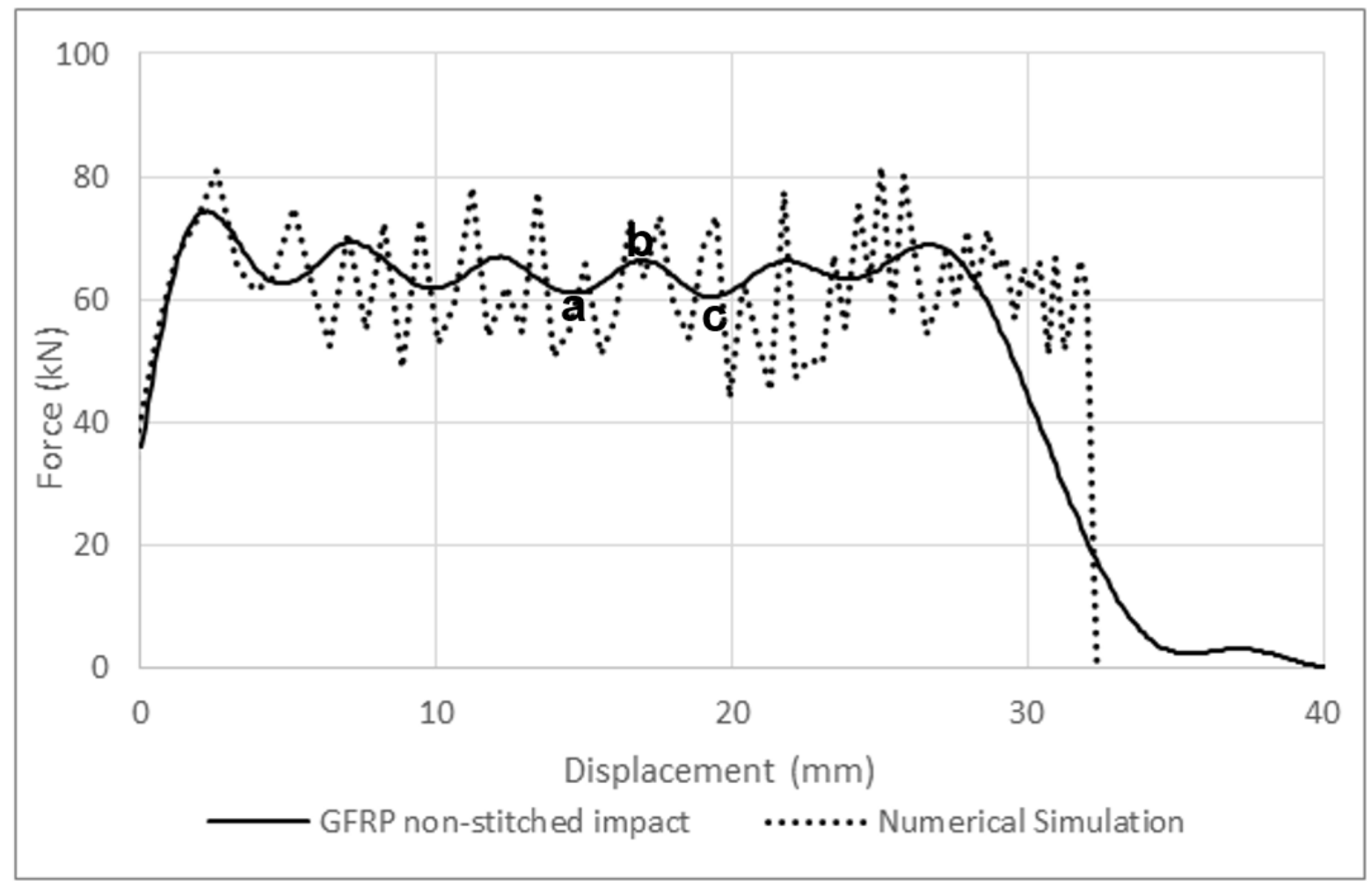

Figure 26. Force-displacement characteristic experimental and numerical comparison [66], (a-b) increase in load and $(\mathrm{b}-\mathrm{c})$ decrease in load.

\subsection{Debris Wedge}

During the progressive crushing process, the fractured material within the Mode-I opening of the tube becomes trapped in the Mode-I opening mode. This increases the friction and affects the crack growth and delamination resistance.

The FEM is not able to simulate this effect if element deletion takes place and does not interfere any longer with the remaining structure. This issue can be resolved by increasing delamination resistance or increasing friction between the shells if a multi-shell configuration is utilised.

Some researchers have tried modelling a debris wedge. McGregor [10] used a predefined debris wedge designed as rigid, and Mamalis [4] defined an intermediate layer trying to represent the pulverised material.

\section{Results}

Based on the finite element findings and calibrations in this paper and briefly explained in Section 3 , the simulations were carried out under quasi-static and impact loading conditions.

\subsection{Material and Experimental Setup}

In this study, the composite sections were fabricated from glass $/$ epoxy $\left(\rho=2250 \mathrm{~kg} / \mathrm{m}^{3}\right)$ with a symmetric twelve-ply quasi-isotropic laminate design of $(-45 / 45 / 0 / 90 / 0 / 90)_{S}$ using hand lay-up techniques. The composite sections were $80 \times 80 \mathrm{~mm}$ with a total thickness of $3 \mathrm{~mm}$ in size.

In quasi-static testing, a $500 \mathrm{kN}$ load cell capacity hydraulic press was used with a $2 \mathrm{~mm} /$ second loading rate. All specimens were allocated with respect to the centre of the stroke for equal load distributions. The stroke displacement for all specimens was kept at $50 \mathrm{~mm}$. The profile of load-displacement consists of load cell and stroke displacement.

In impact testing, a drop tower with an impactor mass of $108.4 \mathrm{~kg}$ was used at $2.0 \mathrm{~m}$ height and $7.022 \mathrm{~m} / \mathrm{s}$ velocity, and a total energy of $2672 \mathrm{~J}$ was applied to each specimen. The mass is dropped from a pre-determined height of $2.0 \mathrm{~m}$ to initiate and record the load 
against time once it reaches the specimen. It will only stop when the applied energy of $2672 \mathrm{~J}$ is absorbed by the specimen. The hammer is then pulled back up by the machine. Once the impactor hits the tube leading edge, the load cell records the force history.

\subsection{Crushed Morphologies}

In this section, the crushed morphologies between experimental and numerical results are compared (see Figure 27). Part a and b represent the quasi-static loading condition, experimental and numerical, respectively. Part $b$ and $c$ represent the impact loading condition, experimental and numerical, respectively. The axial splitting, as mentioned before, is captured by FEA and shown with a large separation between the elements. The double-shell configuration can capture the inner and outer petals' formation in both cases.

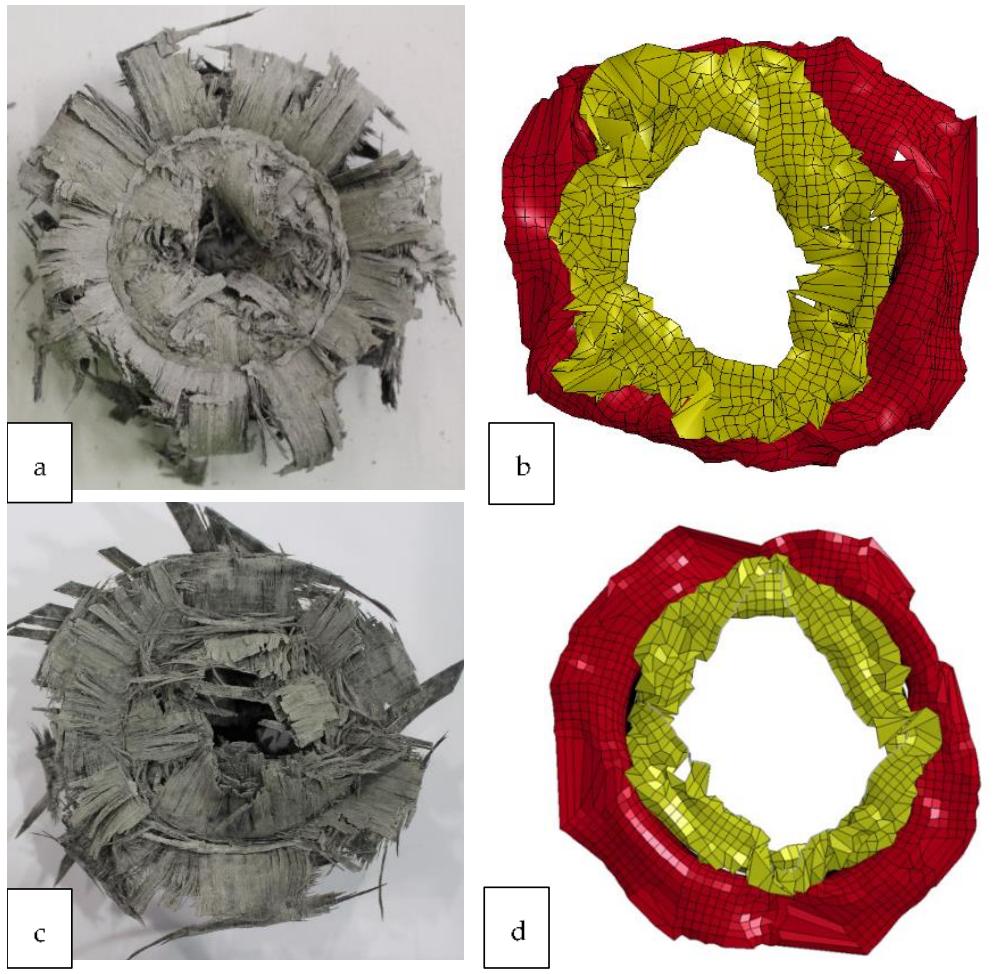

Figure 27. Plane view morphologies, experimental and numerical comparison, (a) crushed under quasi-static experimental, (b) crushed under quasi-static numerical, (c) crushed under impact loading experimental, (d) crushed under impact loading numerical [63,65].

\subsection{Force-Displacement Graphs}

In this section, the force-displacement graphs are shown in Figure 28. Part a represents the quasi-static loading condition, and part $b$ shows the impact loading condition. In this case, the stiffness and the mean crushing force is the main concentration. The stiffness, which is the initial peak in the graph, is followed by the mean crushing force. In part a, the experimental data have a mean crush force of $100 \mathrm{kN}$, an FEA of $98 \mathrm{kN}$, and an initial peak value of $88 \mathrm{kN}$ in both the FEA and experimental studies. In part b, the mean crush force is $69 \mathrm{kN}$ for experimental and $68 \mathrm{kN}$ for numerical, with an initial peak value of $78 \mathrm{kN}$ in both cases. This shows that the FEM has captured and predicted the behaviour of the GFRP composite tubes under quasi-static and impact loading. 

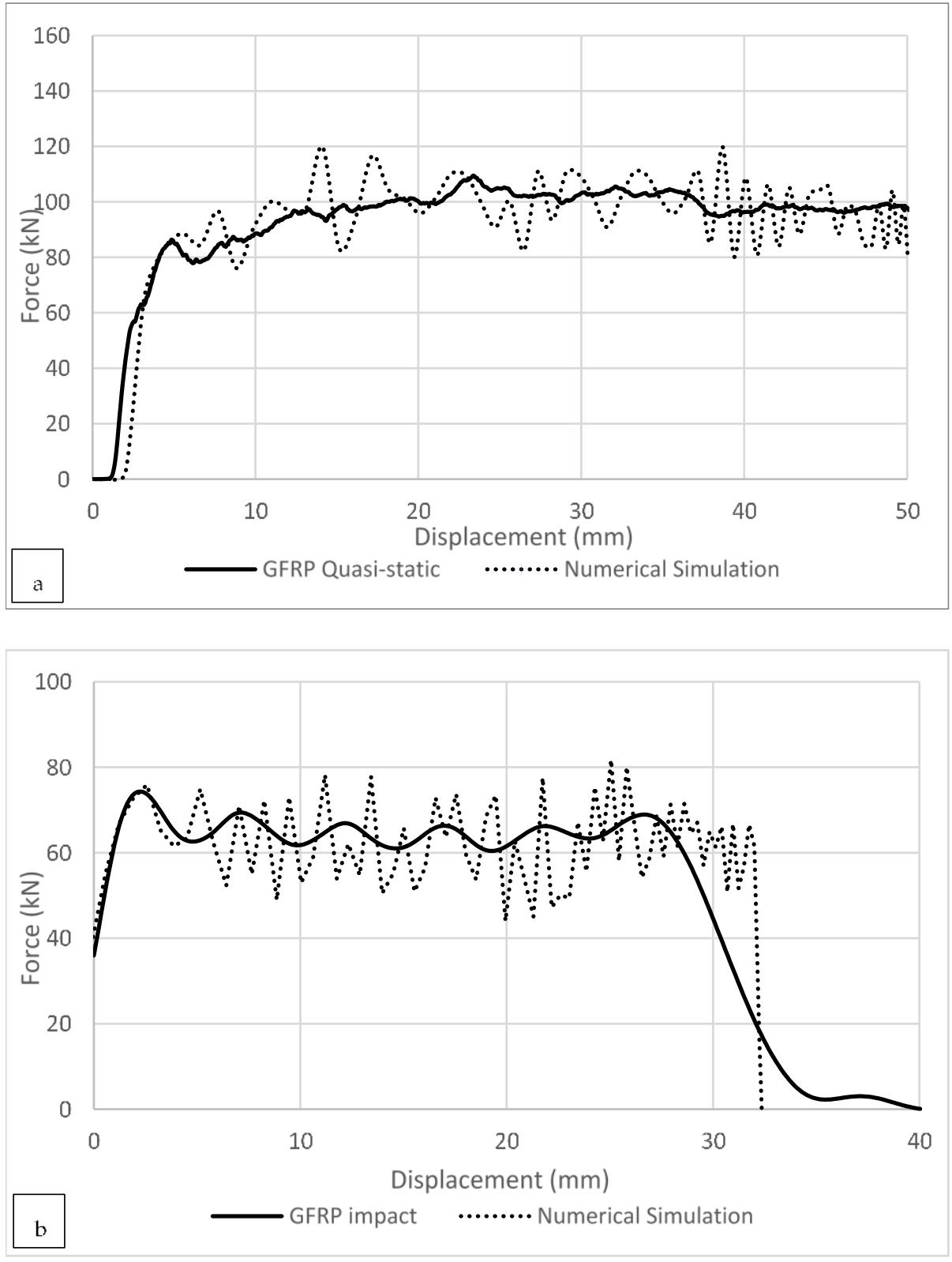

Figure 28. Force-displacement characteristic experimental and numerical comparison [66].

\subsection{Specific Energy Absorption (SEA) Comparison}

The SEA value comparison in this section is to determine the energy absorption capability of the finite element model compared with experimental studies. In this section, the differences between the numerical and experimental studies are compared. In Figure 29, the SEA value of the numerical model under quasi-static loading is $2.6 \%$ off compared with experimental data. The SEA value of numerical studies under impact loading is $3.8 \%$ off compared with experimental data. The aim of this paper is to achieve a $5 \%$ difference and have an efficient model in terms of computational costs and accuracy, which has been achieved. 


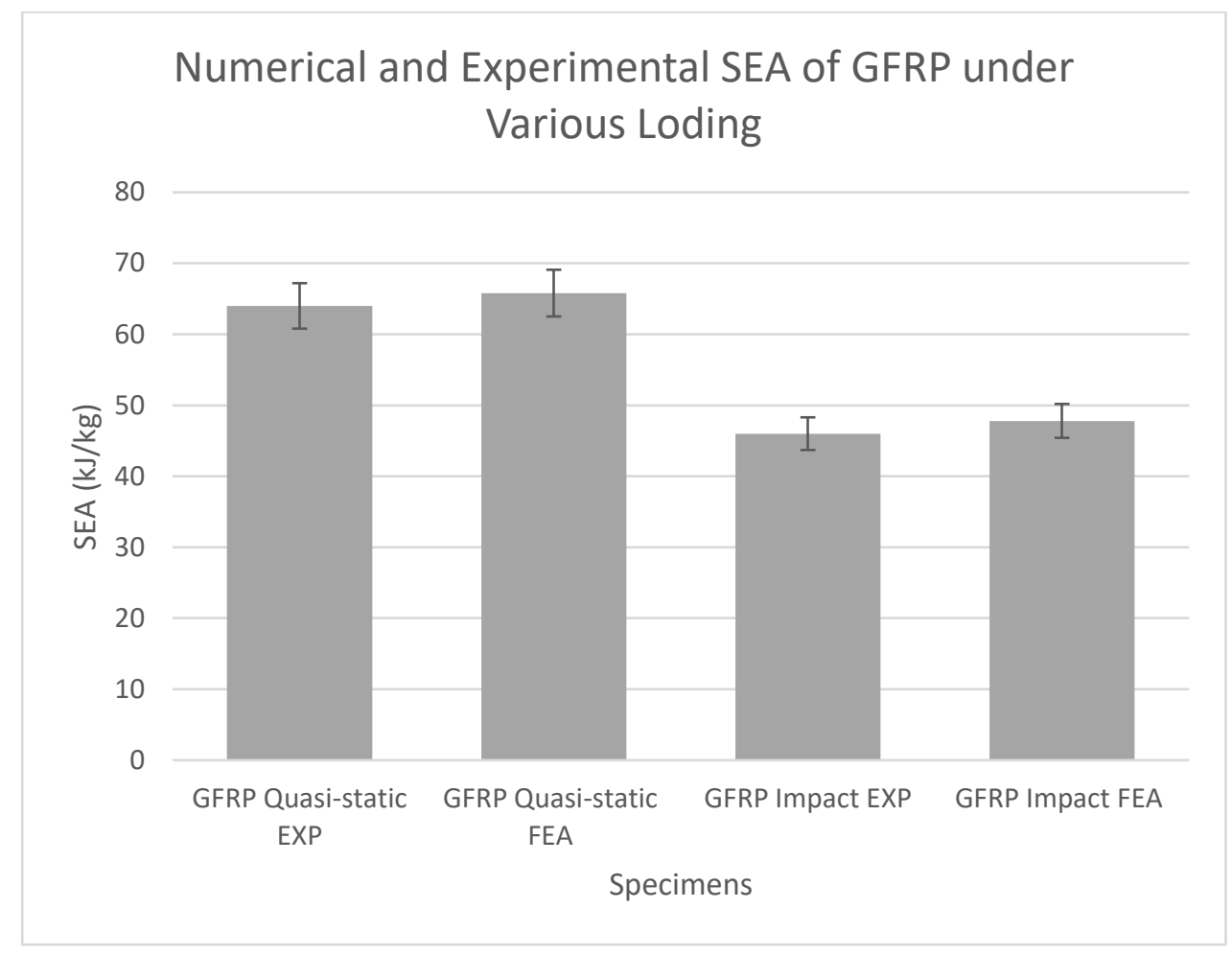

Figure 29. Numerical and experimental SEA of GFRP under Quasi-static and Impact loading conditions [66].

\section{Conclusions}

The aim of this paper was to develop a finite element model using LS-DYNA to simulate the crushing behaviour of composite tubes with a chamfer failure trigger mechanism under various loadings. Various shell configurations were studied, and a multi-layer shell element with double-shell configuration produced accurate enough results with a difference of less than $5 \%$ with minimal computational costs compared with other configurations. This configuration was used to predict energy absorption capability and specific energy abortion, and other considerations were deformation and damage progression of the composite tubes. Each shell element or layer can contain either a single ply or multiple plies. The layers were tied using tiebreak option 8 contact definitions. This contact card has the capability of modelling delamination between the layers through an energy-based approach. The material card of Mat_54 was used to represent each ply, and a few parameters in the material cards were studied to find the optimum configurations to match the experimental studies. SOFT and DFAILC (compression failure strain) were the main parameters that affected the energy absorption capability, and specific energy absorption was influenced by these parameters. The sensitivity of the model was studied against the material model, delamination model, friction and impact velocity. The results show that the model is sensitive towards minimal input change. The simulation results showed that the failure peak load, mean crushing force, and SEA all compared very well with the experimental results.

Numerical models are commonly used to predict the mechanical response of simple to complex geometries as this is a cost-effective approach compared to experimental results. FEM is utilised to predict various conditions and scenarios and relative optimisation takes place; however, numerical models, for instance, the one developed in this paper, have their limitations in showing the fracture and crushed zones on a smaller scale, forcedisplacement characteristics, and debris wedges, which are all contributing factors to energy absorption. Each developed numerical model has its range of validation, which means the model is capable of accurate prediction to a certain level, and the model is incapable of good prediction if the input values exceed the range or the input values are 
amended. It is critical to experimentally obtain this range if various scenarios are intended to be studied [66,67]. Therefore, Double Cantilever Beam (DCB), End-Notched Flexure (ENF), Three Point Bending, compression, tensile testing, and many more can be utilised to improve material behaviour and prediction. Maximising resolution of numerical models can be obtained for various application such as [68,69], by improving prediction of material behaviour i.e., the mechanical properties, via physical and non-physical parameters, the discrepancy between experimental and numerical data can be minimised.

The standard deviation between experimental and numerical studies is very low due to calibration of the model based on trial and error and the parametric study to improve resolution. However, different scenarios were conducted, impact and quasi-static, to further understand the discrepancy between a calibrated model and a different scenario without calibration; hence, in this paper, this was utilised as an indication of prediction. The calibrated model had a discrepancy of 5\% in the experiment, and when the scenario changed, a similar discrepancy was observed (5\%) in the relative experiment.

The calculation errors are all dependent on boundary conditions, mechanical properties inputs, mesh sensitivity and all other parameters discussed in this paper. The model is as accurate as the input values. The calculation error might occur in experimental studies, and measuring the crushed zones, for instance, can make a difference in SEA values.

In conclusion, the developed model in this study has shown to be capable of accurately capturing the crushing behaviour of the tubes with minimal differences whilst being computational cost-efficient. The numerical and experimental studies are in good agreement.

Author Contributions: Methodology, verification and validation, model development, analysis, and evaluation, writing and editing, A.R. writing, review, editing and supervising, H.G. All authors have read and agreed to the published version of the manuscript.

Funding: This research received no external funding.

Institutional Review Board Statement: Not applicable.

Informed Consent Statement: Not applicable.

Data Availability Statement: Not applicable.

Conflicts of Interest: The authors declare no conflict of interest.

$\begin{array}{ll}\text { Abbreviations } \\ \text { CFE } & \text { crush force efficiency } \\ \text { CFRP } & \text { carbon fibre reinforced plastic } \\ \text { GFRP } & \text { glass fibre reinforced plastic } \\ \text { DCB } & \text { double-cantilever beam } \\ \text { 3ENF } & \text { three-point-end-notched flexure } \\ \text { KE } & \text { kinetic energy } \\ \rho & \text { density } \\ \text { A } & \text { cross-sectional area } \\ \text { E } & \text { Young's modulus } \\ \text { F } & \text { load } \\ F_{\text {max }} & \text { initial maximum load } \\ F_{m} & \text { mean load } \\ P_{L} & \text { peak load } \\ G_{12} & \text { shear modulus } \\ G_{I C} & \text { mode-i interlaminar fracture toughness } \\ G_{I I C} & \text { mode-ii interlaminar fracture toughness } \\ \text { SEA } & \text { specific energy absorption }(\mathrm{kj} / \mathrm{kg}) \\ t & \text { wall-thickness } \\ \mathrm{D} & \text { diameter } \\ \mathrm{C} & \text { circumference } \\ \mathrm{L} & \text { axial length } \\ & \end{array}$




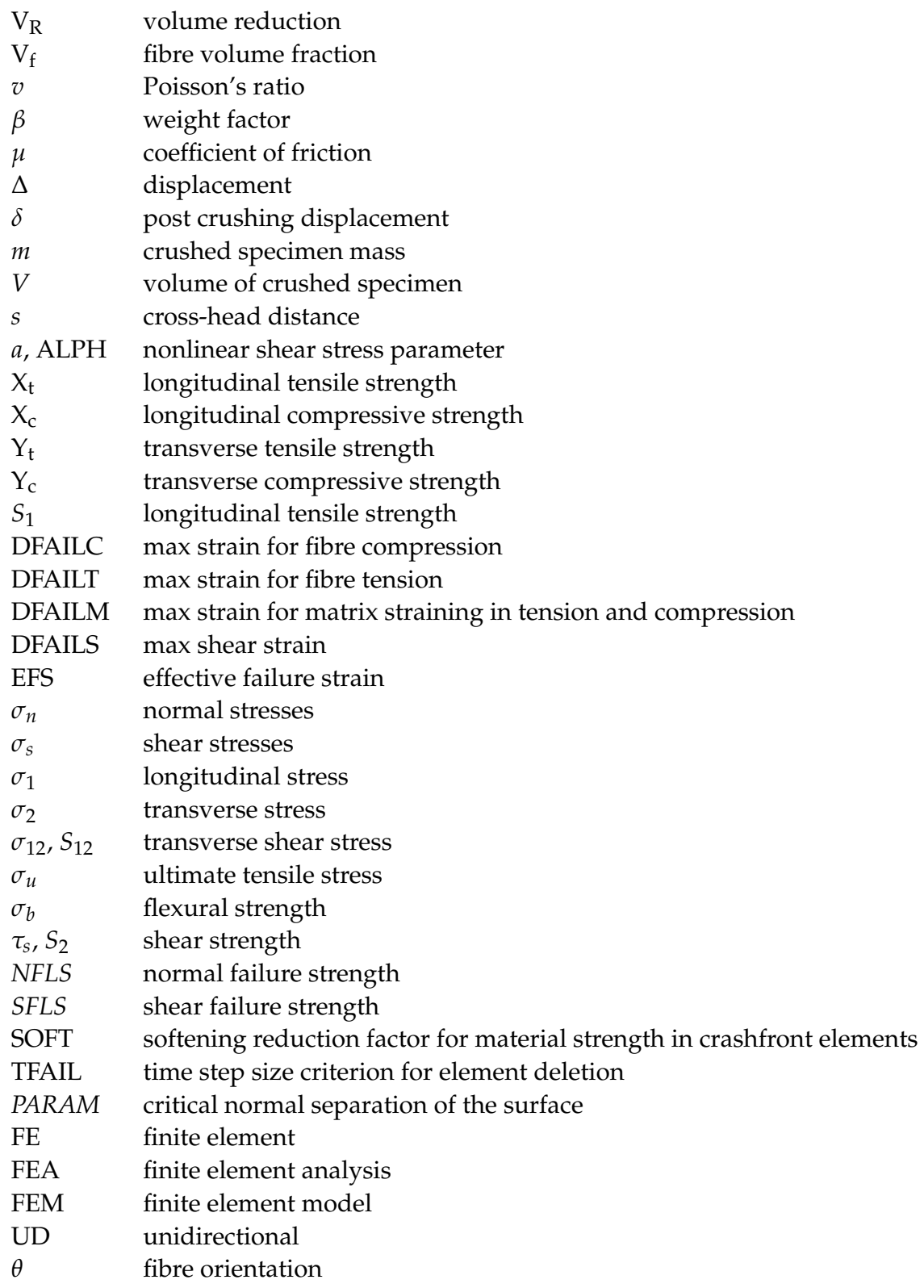

\section{References}

1. Cook, R.D.; Malkus, D.S.; Plesha, M.E. Concepts and Applications of Finite Element Analysis; Wiley Publishing: Hoboken, NJ, USA, 1989.

2. Bisagni, C.; Pietro, G.P.; Fraschini, L.; Terletti, D. Progressive crushing of fiber-reinforced composite structural components of a Formula One racing car. Compos. Struct. 2005, 68, 491-503. [CrossRef]

3. Huang, J.; Wang, X. Numerical and experimental investigations on the axial crushing response of composite tubes. Compos. Struct. 2009, 91, 222-228. [CrossRef]

4. Fu, J.; Liu, Q.; Ma, Y.; Zhang, Z.A. A comparative study on energy absorption of flat sides and corner elements in CFRP square tube under axial compression. Thin-Walled. Struct. 2021, 166, 108080. [CrossRef]

5. Palanivelu, S.; Paepegem, W.; Degrieck, J.; Kakogiannis, D.; Ackeren, J.; Hemelrijck, D. Parametric study of crushing parameters and failure patterns of pultruded composite tubes using cohesive elements and seam. Part I: Central delamination and triggering modelling. Polym. Test 2010, 29, 729-741. [CrossRef]

6. Palanivelu, S.; Paepegem, W.; Degrieck, J.; Kakogiannis, D.; Ackeren, J.; Hemelrijck, D. Parametric study of crushing parameters and failure patterns of pultruded composite tubes using cohesive elements and seam. Part II: Multiple delaminations and initial geometric imperfections. Polym. Test 2010, 29, 803-814. [CrossRef]

7. Bussadori, B.P.; Schuffenhauer, K.; Scattina, A. Modelling of CFRP crushing structures in explicit crash analysis. Compos. Part B-Eng. 2014, 60, 725-735. [CrossRef] 
8. Deleo, F.; Wade, B.; Feraboli, P.; Rassaian, M. Crashworthiness of Composite Structures: Experiment and Simulation. In Proceedings of the 50th AIAA Conference, Palm Springs, CA, USA, 4 May 2009.

9. Wang, Y.J.; Zhang, Z.J.; Xue, X.W.; Zhou, J.; Song, Z.X. Axial and lateral crushing performance of plate-lattice filled square sandwich tubes. Compos. Struct. 2021, 274, 114404.

10. McGregor, C.; Vaziri, R.; Xiao, X. Finite element modelling of the progressive crushing of braided composite tubes under axial impact. Int. J. Impact. Eng. 2010, 37, 662-672. [CrossRef]

11. McGregor, C.; Zobeiry, N.; Vaziri, R.; Poursartip, A. A constitutive model for progressive compressive failure of composites. J Compos. Mater. 2008, 42, 2687-2716. [CrossRef]

12. Xiao, X. Modeling energy absorption with a damage mechanics based composite material model. J. Compos. Mater. 2009, 43, 427-444. [CrossRef]

13. Oshkovr, S.A.; Taher, S.T.; Oshkour, A.A.; Ariffin, A.K.; Azhari, C.H. Finite element modeling of axially crushed silk/epoxy composite square tubes. J. Compos. Struct. 2010, 95, 411-418. [CrossRef]

14. Kim, G.H.; Choi, J.H.; Kweon, J.H. Manufacture and performance evaluation of the composite hat-stiffened panel. Compos. Struct. 2010, 92, 2276-2286. [CrossRef]

15. Chatiri, M.; Gull, T.; Matzenmiller, A. An assessment of the new LS-DYNA layered solid element: Basics, patch simulation and its potential for thick composite structures analysis. In Proceedings of the 7th European LS-DYNA Conference, Salzburg, Austria, 14-15 May 2009.

16. Wagner, W. FE-Modeling of fiber reinforced polymer structures. In Proceedings of the 5th World Congress on Computational Mechanics, Vienna, Austria, 7-12 July 2002.

17. Feraboli, P. Development of a corrugated test specimen for composite material energy absorption. J. Compos. Mater. 2008, 42, 229-256. [CrossRef]

18. Greco, F.; Luciano, R. A theoretical and numerical stability analysis for composite micro-structures by using homogenization theory. Compos. Part B Eng. 2011, 42, 382-401. [CrossRef]

19. Sun, H.; Di, S.; Zhang, N.; Pan, N.; Wu, C. Micromechanics of braided composites via multivariable FEM. Comput. Struct. 2003, 81, 2021-2027. [CrossRef]

20. Tabiei, A.; Aminjikarai, B.S. A strain-rate dependent micro-mechanical model with progressive post-failure behavior for predicting impact response of unidirectional composite laminates. Compos. Struct. 2009, 88, 65-82. [CrossRef]

21. Crashworthiness Working Group of the CMH-17. Simulation of the quasi-static crushing of a fabric composite plate. Abaqus Technol. Brief 2011. Available online: https://imechanica.org/files/Automotive-SIMULIA-Tech-Brief-11-Simulation-Quasistatic-Crushing-Full.pdf (accessed on 1 December 2021).

22. Feindler, N.; Drechsler, K.; Doll, J. Test method to analyse the energy absorption of composite material using flat coupon testing In Proceedings of the 5th International Conference on Composites Testing and Model Identification, Lausanne, Switzerland, 14-16 February 2011.

23. Borovkov, A.; Palmov, V.; Banichuk, N.; Saurin, V.; Barthold, F.; Stein, E. Macro-failure criterion for the theory of laminated composite structures with free edge delaminations. Comput. Struct. 2000, 76, 195-204. [CrossRef]

24. Johnson, A.; Pickett, A. Impact and crash modelling of composite structures: A challenge for damage mechanics. In Proceedings of the 9th User Conference EURO-PAM, Darmstadt, Germany, 7-8 October 1999.

25. Greve, L.; Andrieux, F. Deformation and failure modelling of high strength adhesives for crash simulation. Int. J. Fract. 2007, 143, 143-160. [CrossRef]

26. Tang, C.Y.; Tsui, C.P.; Lin, W.; Uskokovic, P.S.; Wang, Z.W. Multi-level finite element analysis for progressive damage behavior of HA/PEEK composite porous structure. Compos. Part B Eng. 2013, 55, 22-30. [CrossRef]

27. Barut, A.; Madenci, E.; Tessler, A.; Starnes, J.H., Jr. A new stiffened shell element for geometrically nonlinear analysis of composite laminates. Comput. Struct. 2000, 77, 11-40. [CrossRef]

28. Mohite, P.M.; Upadhyay, C.S. Region-by-region modeling of laminated composite plates. Comput. Struct. 2007, 85, 1808-1827. [CrossRef]

29. Holzapfel, M.; Grundolf, K.; Adamski, P.; Elsenhans, H.; Doll, J.; Hambrecht, T. Untersuchungen zur Modellierung von Strukturen aus FKV unter Crashbelastung mit. Hilfe von Mehrschalen modellierungen. In Proceedings of the 7th German LS-DYNA Users Conference, Bamberg, Germany, 30 September 2008.

30. Feindler, N. Charakterisierungs- und Simulationsmethodik zum Versagensverhalten Energieabsorbierender Faserverbundstrukturen. Ph.D. Thesis, Technical University of Munich, Munich, Germany, 2012.

31. Joosten, M.W.; Dutton, S.; Kelly, D. Experimental and numerical investigation of the crushing response of an open section composite energy absorbing element. Compos. Struct. 2011, 93, 682-689. [CrossRef]

32. Hussain, N.N.; Regalla, S.P.; Rao, Y.V.D. Comparative Study of Trigger Configuration for Enhancement of Crashworthiness of Automobile Crash Box Subjected to Axial Impact Loading. Procedia Eng. 2017, 173, 1390-1398. [CrossRef]

33. Johnson, A.F. Modelling fabric reinforced composites under impact loads. Compos. Appl. Sci. Manuf. 2001, 32, 1197-1206. [CrossRef]

34. Abdallah, M.H.; Brainmah, A. Numerical design optimization of the fiber orientation of glass/phenolic composite tubes based on tensile and radial compression tests. Compos. Struct. 2021, 114898, in press. [CrossRef] 
35. Reiner, J.; Zobeiry, N.; Vaziri, R. A stacked sublaminate-based damage-plasticity model for simulating progressive damage in composite laminates under impact loading. Thin-Walled Struct. 2020, 156, 107009. [CrossRef]

36. Reiner, J. A practical approach for the non-local simulation of progressive damage in quasi-isotropic fibre-reinforced composite laminates. Compos. Struct. 2021, 265, 113761. [CrossRef]

37. Chambe, J.; Bouvet, C.; Dorival, O.; Ferrero, J.F. Energy absorption capacity of composite thin-wall circular tubes under axial crushing with different trigger initiations. J. Compos. Mater. 2019, 54, 1281-1304. [CrossRef]

38. Reiner, J.; Feser, T.; Waimer, M.; Poursartip, A.; Voggenreiter, H.; Vaziri, R. Axial crush simulation of composites using continuum damage mechanics: FE software and material model independent considerations. Compos. Part B Eng. 2021, $225,109284$. [CrossRef]

39. Xiao, X.; Botkin, M.E.; Jahnson, N.L. Axial crush simulation of braided carbon tubes using MAT58 in LS-DYNA. Thin-Walled Struct. 2009, 47, 740-749. [CrossRef]

40. Pinho, S.T.; Camanho, P.P.; De Moura, M.F. Numerical simulation of the crushing process of composite materials. Int. J. Crashworthiness 2004, 9, 263-276. [CrossRef]

41. Chiu, L.N.S.; Falzon, B.G.; Boman, R.; Chen, B.; Yan, W. Finite element modelling of composite structures under crushing load. Compos. Struct. 2015, 131, 215-228. [CrossRef]

42. Siromani, D.; Henderson, G.; Mikita, D.; Mirarchi, K.; Park, R.; Smolko, J.; Awerbuch, J.; Tan, T.-M. An Experimental Study on the Effect of Failure Trigger Mechanisms on the Energy Absorption Capability of CFRP Tubes under Axial Compression. Compos. Part A 2014, 64, 25-35. [CrossRef]

43. Siromani, D.; Awerbuch, J.; Tan, T.-M. Finite element modeling of the crushing behavior of thin-walled CFRP tubes under axial compression. Compos. B Eng. 2014, 64, 50-58. [CrossRef]

44. Seat Crashworthiness Improvement on Large Aeroplanes-Dynamic Testing 16g. 2018. Available online: https://www.easa europa.eu/system/files/dfu/NPA\%202013-20.pdf (accessed on 23 January 2018).

45. Tong, L.; Mouritz, A.P.; Bannister, M. 3D Fibre Reinforced Polymer Composites; Elsevier: Amsterdam, The Netherlands, 2002; ISBN 9780080525822

46. Boeing Demonstrates Use of Stitching Machine for Carbon Fiber Fabric. 1997. Available online: http:/ /aviationweek.com/awin/ boeing-demonstrates-use-stitching-machine-carbon-fiber-fabric (accessed on 18 September 2016).

47. Hallquist, J.O. LS-DYNA Theory Manual; Livermore Software Technology Corporation: Livermore, CA, USA, 2006.

48. Chang, F.K.; Chang, K.Y. Post-Failure Analysis of Bolted Composite Joints in Tension or Shear-Out Mode Failure. J. Compos. Mater. 1987, 21, 809. [CrossRef]

49. Hashin, Z. Failure Criteria for Unidirectional Fiber Composites. J. Appl. Mech. 1980, 47, 329-334. [CrossRef]

50. Tsai, S.W.; Wu, E.M. A General Theory of Strength for Anisotropic Materials. J. Compos. Mater. 1971, 5, 58. [CrossRef]

51. Zheng, X. Nonlinear Strain Rate Dependent Composite Model for Explicit Finite Element Analysis. Ph.D. Thesis, University of Akron, Akron, OH, USA, 2006.

52. Krishnamoorthy, S.K.; Hoptner, J.; Kopp, G.; Friedrich, H.E. Prediction of structural response of FRP composites for conceptual design of vehicles under impact loading. In Proceedings of the 8th European LS-DYNA Users Conference, Strasbourg, France, 23-24 May 2011.

53. Reuter, C.; Troster, T. Crashworthiness and numerical simulation of hybrid aluminium-CFRP tubes under axial impact. ThinWalled. Struct. 2017, 117, 1-9. [CrossRef]

54. Mamalis, A.G. The static and dynamic axial collapse of CFRP square tubes: Finite element modelling. Compos. Struct. 2006, 74, 213-225. [CrossRef]

55. Yousefi, A.K. Buckling and Crack Propagation Analysis of Composite Laminated Structures. Master's Thesis, Kingston University, London, UK, 2016.

56. Matzenmiller, A.; Lubliner, J.; Taylor, R.L. A constitutive model for anisotropic damage in fiber composites. Mech. Mater. 1995, 20, 125-152. [CrossRef]

57. Bala, S.; Day, J. Tie-Break Contacts in Ls-Dyna, Livemore Software Technology Corporation. 2010. Available online: https: / / ftp.lstc.com/anonymous/outgoing/support/PRESENTATIONS/Crash_Guidelines.pdf (accessed on 1 December 2021).

58. Jayasinghe, P.D.N. New Development on Mode-I Delamination Failure of FRP Composites. Bachelor's Thesis, Kingston University, London, UK, 2016.

59. Ghasemnejad, H.; Blackman, B.R.K.; Hadavinia, H.; Sudall, B. Experimental studies on fracture characterisation and energy absorption of GFRP composite box structure. Compos. Struct. 2008, 88, 253-261. [CrossRef]

60. Ghasemnejad, H.; Hadavinia, H. Off-axis crashworthiness characteristic of woven glass/epoxy composite box structures. J. Reinf. Plast. Comp. 2010, 29, 2306-2330. [CrossRef]

61. Rabiee, A.; Ghasemnejad, H. Progressive Crushing of Polymer Matrix Composite Tubular Structures: Review. Open J. Compos. Mater. 2017, 7, 14-48. [CrossRef]

62. Rabiee, A.; Ghasemnejad, H. Effect of multi stitched locations on high speed crushing of composite tubular structures. Compos. Part B Eng. 2016, 100, 164-175. [CrossRef]

63. Rabiee, A.; Ghasemnejad, H. Improvement of Specific Energy Absorption of Composite Tubular Absorbers using Various Stitching Pattern Designs. Appl. Compos. Mater. 2020, 27, 717-738. [CrossRef] 
64. Rabiee, A.; Ghasemnejad, H. Lightweight design to improve crushing behaviour of multi-stitched composite tubular structures under impact loading. Thin-Walled Struct. 2019, 135, 109-122. [CrossRef]

65. Rabiee, A.; Ghasemnejad, H. Laminate Tailoring of Composite Tubular Structures to Improve Crashworthiness Design at Off-Axis Loading. Open J. Compos. Mater. 2018, 8, 3. [CrossRef]

66. Rabiee, A. Lightweight Design of Multi-Stitched Composite Crash Absorbers to Improve Specific Energy Absorption Capability under Quasi-Static and Impact Loading. Ph.D. Thesis, Cranfield University, Cranfield, UK, 2018.

67. Omidali, M.; Khedmati, M.R. Numerical investigation on novel geometrical configuration for adhesively bonded T-joint between aluminium and sandwich panel. Thin-Walled Struct. 2018, 131, 122-134. [CrossRef]

68. Khosravani, M.R.; Weinberg, K. Characterization of sandwich composite T-joints under different ageing conditions. Compos. Struct. 2018, 197, 80-88. [CrossRef]

69. Ramaswamy, S.; Shariff, Z.A.; Munaf, A.A.; Leo, I.J.; Gnanaraj, S.J.P.; Jeshurun, S.B. Study on application of higher order lamination plate theory over various applications of natural fiber cross-ply composites. Mater. Proc. 2021, in press. [CrossRef] 